\title{
"COMPLIANCE" EMPRESARIAL: LA LABOR DE EMPRESA MÁS ALLÁ DE LOS BIENES JURÍDICO-PENALES. PERSPECTIVA ESPAÑOLA
}

Julio Ballesteros Sánchez*

Resumen: Este artículo analiza, desde una óptica de derecho comparado, el vínculo que une el estudio del fenómeno del criminal compliance, capaz de evitar o reducir hasta niveles de tolerancia social los riesgos emanados de la actividad empresarial, con las prioridades estratégicas globales (seguridad humana, desarrollo sostenible) establecidas por organismos internacionales como, por ejemplo, Naciones Unidas. Se considera que este enfoque servirá para que los Estados democráticos fortalezcan el Estado de derecho y, particularmente, las pautas legales relativas a la prevención en materia de compliance dentro y fuera de las fronteras nacionales. Así, el presente trabajo, para cuya

* Doctor en Derecho Penal por la Universidad de Salamanca (España); máster en Derecho Penal por la misma universidad; y máster en Cumplimiento Normativo en Materia Penal por la Universidad Castilla-La Mancha. El artículo se enmarca como parte de mi actividad investigadora: Proyecto DER 2016-79705-R; GIR Programas de Cumplimiento y Responsabilidad Penal de las Personas Jurídicas de la Universidad de Salamanca; investigador visitante de Flacso Sede Ecuador y miembro del grupo de investigación "Políticas públicas, seguridad internacional y gobernanza global” de la Universidad Europea de Madrid. Profesor de Derecho en la Universidad de Salamanca (España). Correo-e: jbs@usal.es. Fecha de recepción: 7 de julio de 2020. Fecha de aceptación: 12 de enero de 2021. Para citar el artículo: Julio Ballesteros SÁnchez. " Compliance’ empresarial: la labor de empresa más allá de los bienes jurídico-penales. Perspectiva española”, Revista Derecho Penal y Criminología, vol. 41, n. ${ }^{\circ} 111$, julio-diciembre de 2020, Bogotá, Universidad Externado de Colombia, pp. 13-60. DOI: https://doi.org/10.18601/01210483.v41n111.02. 
redacción se examinó una variedad de documentos estratégicos penales y extrapenales, advierte que el modelo preventivo ofrecido por el compliance en aras de proteger bienes jurídico-penales puede ser útil para contener otros riesgos que causan inseguridad en las sociedades actuales.

Palabras clave: criminal compliance; derechos humanos; seguridad nacional; seguridad humana; Objetivos de Desarrollo Sostenible.

\title{
BUSINESS COMPLIANCE: COMPANY'S DUTIES BEYOND LEGAL GOODS PROTECTED BY CRIMINAL LAW. SPANISH PERSPECTIVE
}

\begin{abstract}
This paper analyzes, the link that ties the study of the phenomenon of criminal compliance with global strategic priorities (human security, sustainable development) established by international organizations such as the United Nations) from a comparative law perspective. The phenomenon of criminal compliance is capable of avoiding or reducing the risks arising from business activity to levels of social tolerance. It is considered that this approach will serve for democratic States to strengthen the rule of law and, particularly, the legal guidelines related to the prevention of compliance within and outside national borders. Thus, the present work, for the drafting of which a variety of strategic criminal and extra-criminal documents were examined, warns that the preventive model offered by compliance in order to protect legal-criminal assets may be useful to contain other risks that cause insecurity in current societies.
\end{abstract}

Keywords: criminal compliance; human rights; national security; human security; Sustainable Development Goals.

\footnotetext{
"Cuanto más te observo, mejor te comportas."

JeREMy Bentham, Writings on the Poor Law.
}

\section{INTRODUCCIÓN}

En 1977 los Estados Unidos aprobó la Ley de Prácticas Corruptas (Foreign Corrupt Practices Act) ${ }^{1}$. Con ello, los académicos empezarían a enfocarse en el estudio del compliance, pues era visible que las empresas estaban siendo utilizadas para encubrir

1 En rigor, fue en 1991, con la aprobación de las Federal Sentencing Guidelines for Organizations, cuando el estudio del compliance despuntó, pues este se consideraría un atenuante en caso de que la persona jurídica fuera condenada. Además, la existencia del programa de cumplimiento permitía 
crímenes dentro y fuera de las fronteras, lo cual tenía fatales repercusiones para el Estado. En este punto es importante reconocer que el hecho de que el Estado prestara atención a las personas jurídicas como potenciales sujetos criminales constituye un punto de inflexión en el derecho penal nacional e internacional.

Con el tiempo, los países han ido incorporando nuevas pautas jurídicas que buscan disuadir a dichas entidades de participar en conductas delictivas o de ser protagonistas de ellas. Según nuestro criterio, el Estado en estos países ha actuado oportunamente, por proponer medidas que no son solo punitivas, sino que instan a las empresas a un autocontrol de naturaleza preventiva, generando con ello una interacción de confianza frente al innegable poder económico que ostentan.

Sin embargo, a pesar del aceptable papel legislativo que han desempeñado los Estados, hay dos cuestiones fundamentales que han jugado en contra de la persecución efectiva de la delincuencia corporativa. La primera de ellas tiene que ver con las limitadas capacidades policiales, fiscales e inspectoras de las que adolece el Estado a la hora de lidiar con complejos casos de criminalidad corporativa, donde, además, en muchos casos se dan graves casos de corrupción que implican a políticos o destacados empresarios. La ineficacia en la persecución de los delincuentes de cuello blanco ha provocado un debilitamiento de la confianza en las instituciones y en los partidos políticos. Todo ello, en un contexto de crisis económica mundial.

En cuanto a la segunda, bien se sabe que la sociedad y la actividad económica de los agentes y sus prácticas les llevan la delantera a la función legislativa del Estado y a las instituciones que velan por el cumplimiento de la ley. A ello hay que sumar tres factores: la creciente complejidad de las relaciones económicas; el sentimiento de animadversión hacia el peligro de la ciudadanía dentro de una sociedad del riesgo; y los nuevos retos que supone la globalización y las nuevas tecnologías. Ya no se trata únicamente de ofrecer respuestas a los tradicionales delitos como el crimen organizado y la corrupción pública, cuyos sujetos activos eran los individuos y los funcionarios del Estado. Ahora se añaden modernas estrategias delictivas en los anteriores delitos, pero también en otros de repercusión más reciente como la financiación del terrorismo internacional, el espionaje corporativo y los daños ambientales a gran escala que provocan y aceleran el cambio climático, en los que las empresas son los principales actores. Si no estamos a la altura de los riesgos globales que nuestras sociedades enfrentan en la actualidad, estaremos ofreciendo una "válvula de oxígeno" a la crimina$\operatorname{lidad}^{2}$. En efecto, ha cambiado la etiología criminal y ello ha provocado el desarrollo del derecho del penal económico y de la empresa y la criminología corporativa.

estar en una mejor posición para negociar con los fiscales acuerdos de no enjuiciamiento o de enjuiciamiento en diferido.

2 Laura Zúñiga Rodríguez. "El concepto de criminalidad organizada transnacional: problemas y 
Ante la amenaza que suponen estos delitos en el marco de la globalización y las nuevas tecnologías, es alentador el trabajo de varios autores que aluden a una cuarta generación de derechos humanos. En ella se pone el acento en los derechos del consumidor, la democracia ${ }^{3}$, los problemas ecológicos, el uso de las ciencias y la tecnología, entre otros $^{4}$, sumándose estos a los de primera, segunda y tercera generación propuestos por Karel Vasak, que se centraron en la libertad y la participación en la vida política, la equidad y la solidaridad ${ }^{5}$. En relación con esta línea de investigación, hay trabajos de referencia que estudian la seguridad humana (Naciones Unidas) y la seguridad nacional (documentos estratégicos de cada Estado). No obstante, existe un vacío en la academia penal sobre cómo el déficit estructural organizativo de las empresas, estado de cosas contrario a Derecho, puede conducir claramente hacia un deterioro de la seguridad humana y un riesgo para la seguridad nacional. Este trabajo pretende poner de relieve la falta de tratamiento dogmático de dicho tema a fin de aportar una primera aproximación.

El objetivo principal de este artículo es analizar el vínculo existente entre el estudio del fenómeno del compliance, capaz de evitar o reducir hasta niveles de tolerancia social los riesgos derivados de la actividad empresarial, y las prioridades estratégicas globales (seguridad humana, objetivos de desarrollo sostenible) establecidas por organismos internacionales como Naciones Unidas. Se considera que este enfoque será de utilidad para que los Estados democráticos fortalezcan el Estado de derecho $\mathrm{y}$, particularmente, las pautas legales relativas a la prevención en materia de compliance dentro y fuera de las fronteras nacionales. El modelo preventivo que ofrecen los programas de cumplimiento para la protección de bienes jurídico-penales ${ }^{6}$ puede

propuestas", en AA. Vv. Política criminal ante el reto de la delincuencia transnacional, Valencia, Tirant lo Blanch, 2016, p. 164.

3 Gonzalo Altamirano Dimas. "Los derechos humanos de cuarta generación. Un acercamiento", Estudios [en línea]. Centro de Estudios Sociales y de Opinión Pública (CESOP), Cámara de diputados LXII [México], agosto de 2017, p. 21, disponible en [http://www5.diputados.gob.mx/index.php/camara/ Centros-de-Estudio/CESOP/Estudios-e-Investigaciones/Estudios/Los-derechos-humanos-de-cuartageneracion.-Un-acercamiento] (consulta: 22 de mayo de 2020).

4 Juan Carlos Riofrío Martínez-Villalba. "La cuarta ola de derechos humanos: los derechos digitales", Revista Latinoamericana de Derechos Humanos, vol. 25, n. ${ }^{\circ}$ 1, I semestre de 2014, p. 16, disponible en [https://www.corteidh.or.cr/tablas/r33897.pdf] (consulta: 14 de mayo de 2020).

5 Karel Vasak. "Human Rights: A Thirty-Year Struggle: the Sustained Efforts to give Force of law to the Universal Declaration of Human Rights", Unesco Courier, vol. 30, n. ${ }^{\circ} 11,1977$; Antonio Enrique Pérez Luño. "Los derechos humanos hoy: perspectivas y retos XXII Conferencias Aranguren”, Isegoría . Revista de Filosofía Moral y Política, n. . 51, julio/diciembre de 2014, p. 471, disponible en [http:// isegoria.revistas.csic.es/index.php/isegoria/article/view/870/872] (consulta: 7 de marzo de 2020).

6 En España, la existencia de un programa de cumplimiento normativo puede atenuar o eximir de responsabilidad penal a la persona jurídica que sea procesada. En consecuencia, el artículo 31 bis del Código Penal recoge las características que debe cumplir el compliance program si quiere ser calificado de idóneo y eficaz en sede judicial. En concreto, el artículo 31 bis apartado 1 numeral 5 del Código Penal afirma que los programas de cumplimiento " $1 .{ }^{\circ}$ Identificarán las actividades en cuyo ámbito puedan ser cometidos los delitos que deben ser prevenidos. 2. ${ }^{\circ}$ Establecerán los protocolos o 
ser útil para contener riesgos de una naturaleza distinta que causan inseguridad en las sociedades actuales. En el ámbito mundial, esto redundará en el cumplimiento integral de la declaración universal de derechos humanos, tratados suscritos y otras normas, así como también les permitirá ofrecer un mejor seguimiento y monitoreo de los Objetivos de Desarrollo Sostenible, al instar a que tanto la responsabilidad social corporativa como la protección de derechos humanos sean incluidas en las preocupaciones del compliance. También tendrá un impacto en el ámbito local, por blindar su agenda en seguridad nacional y el bienestar social general.

Así las cosas, este trabajo se estructura de la siguiente manera. Una vez presentada la introducción, se procede a desarrollar el tema en cuestión. La sección 1 contextualiza el reconocimiento de los programas de cumplimiento y de la responsabilidad penal de las corporaciones por los Estados para frenar a las grandes empresas existentes en las sociedades modernas de cometer actividades delictivas, dado que ello puede derivar en el deterioro del Estado de bienestar y la lesión del Estado de derecho en las democracias. La sección 2 aborda los ámbitos de expansión del compliance. A saber, los derechos humanos, la seguridad humana, la seguridad nacional y el desarrollo sostenible. Algunos países se han ubicado en la vanguardia de la protección de los derechos humanos, aunque difieren en su carácter imperativo, lo cual se observa, por ejemplo, en casos como los de España y Francia, en el Plan de Acción Nacional de Empresas y Derechos Humanos y el Plan de Vigilancia (Loi n. ${ }^{\circ}$ 2017-399), ambos de 2017 , respectivamente. En este punto, el estudio se divide en dos secciones.

En la primera sección se pone de relieve la idoneidad del compliance en la prevención de riesgos empresariales que entran en conflicto con los derechos humanos y en cómo la corrupción que se origina en el marco de la delincuencia empresarial, afecta a la seguridad nacional y al desarrollo sostenible. Así mismo, en esta sección se revisa el concepto de seguridad humana y sus distintos tipos. Igualmente, se establece una correspondencia de los tipos de seguridad con diferentes problemas sociales, laborales y ambientales ${ }^{7}$ y se identifica un ejemplo de conducta corporativa para cada tipo.

procedimientos que concreten el proceso de formación de la voluntad de la persona jurídica, de adopción de decisiones y de ejecución de las mismas con relación a aquéllos. 3. ${ }^{\circ}$ Dispondrán de modelos de gestión de los recursos financieros adecuados para impedir la comisión de los delitos que deben ser prevenidos. $4 .^{\circ}$ Impondrán la obligación de informar de posibles riesgos e incumplimientos al organismo encargado de vigilar el funcionamiento y observancia del modelo de prevención. 5. ${ }^{\circ}$ Establecerán un sistema disciplinario que sancione adecuadamente el incumplimiento de las medidas que establezca el modelo. $6{ }^{\circ}$ Realizarán una verificación periódica del modelo y de su eventual modificación cuando se pongan de manifiesto infracciones relevantes de sus disposiciones, o cuando se produzcan cambios en la organización, en la estructura de control o en la actividad desarrollada que los hagan necesarios".

7 La criminalidad ambiental puede entenderse como una amenaza para la seguridad nacional y el desarrollo económico y social. Al respecto, Eduardo Pitrez de Aguilar Correa, "Conexión Derecho penal: la reconfiguración subjetiva, normativa y funcional de la política criminal en la sociedad red", en AA. Vv. Política criminal ante el reto de la delincuencia transnacional, Valencia, Tirant lo Blanch, 2016 , p. 53 
Mientras, en la segunda sección, se destaca la importancia de incluir los compromisos asumidos por las empresas en el marco de la responsabilidad social corporativa en el modelo de criminal compliance propuesto por el código penal español, puesto que no basta únicamente con una respuesta estatal. Por último, en el trabajo se ilustra la relación que existe entre los Objetivos de Desarrollo Sostenible y sus metas, asignándose determinados ejemplos de cumplimiento o delincuencia empresarial para cada bloque.

\section{RESPONSABILIDAD PENAL DE LAS PERSONAS JURÍDICAS $Y$ "COMPLIANCE" PENAL: UNA RESPUESTA NECESARIA EN LA SOCIEDAD ACTUAL}

El mundo actual cambia a una velocidad vertiginosa que nuestras instituciones, legislaciones y estudios tardan en digerir. Además, la democracia no pasa por sus mejores momentos, ya que se ha producido un deterioro de su funcionamiento con el correspondiente menoscabo del Estado del bienestar en España y la Unión Europea ${ }^{8}$, al que se le suma una crisis de confianza de los ciudadanos en las administraciones públicas y en los partidos políticos ${ }^{9}$. Tampoco en Colombia son buenos tiempos, respecto de lo cual el profesor García Echeverría afirma: “[N]o hemos superado la barrera del subdesarrollo económico, ni tampoco hemos mejorado efectivamente las condiciones de vida de la mayoría de las personas para otorgarles bienestar" 10 . En el último año las marchas y protestas contra el Gobierno han sido una constante. La falta de inversión en políticas sociales ha sido uno de los principales motivos, pero también el conflicto armado ${ }^{11}$, la muerte de líderes sociales e indígenas y la corrupción $^{12}$ han incrementado la crispación ciudadana ${ }^{13}$.

8 Como ha señalado George, "Se está desarrollando una intensa ofensiva contra el Estado del Bienestar y el modelo social europeo, cuya finalidad es eliminar todos los logros obtenidos por los trabajadores durante las últimas seis o siete décadas". Susan George. Los usurpadores. Cómo las empresas transnacionales toman el poder, Barcelona, Icaria, 2015, p. 27.

9 En consecuencia, para Maza Martín se debería incluir dentro del régimen de responsabilidad penal de los partidos políticos conductas propias de la Ley Orgánica 5/1985, del 19 de junio, del Régimen Electoral. En este sentido, se incluirían conductas cómo: falseamiento de cuentas electorales; propaganda electoral; delitos en materia de encuestas electorales; delitos tendentes a cambiar el sentido del voto; alteración del orden del acto electoral; calumnias e injurias en campaña electoral. José Manuel Maza Martín. Delincuencia electoral y responsabilidad penal de los partidos políticos. Madrid, Wolters Kluwers, 2018, pp. 412-413.

10 “Por qué no mejora el bienestar de los colombianos?”, Dinero (Sección Economía: entrevista a Luis García Echeverría), 27 de septiembre de 2019, disponible en [https:/www.dinero.com/economia/ articulo/a-que-se-deben-los-pocos-avances-en-el-bienestar-de-los-colombianos/277323] (consulta: 13 de marzo de 2020).

11 Colombia ocupa el puesto 140 de un total de 163 países en el Índice de Paz Global. Vid. Institute For Economics \& Peace. Global, Index, Peace Index 2020, Measuring Peace in a Complex World. Sydney, June 2020, p.9, disponible en [http://visionofhumanity.org/app/uploads/2020/06/GPI_2020_web.pdf] (consulta: 13 de julio de 2020).

12 Colombia está ubicada en el puesto 96 dentro del Índice de Percepción de la Corrupción de Transparencia Internacional. Comparte esta posición con países como Etiopía, Tanzania, Gambia y Vietnam. 
Por otro lado, debemos tener en cuenta que nos encontramos inmersos en sociedades líquidas, aceleradas, competitivas, desiguales ${ }^{14}$ y tecnológicas en la que los ciudadanos son especialmente vulnerables. Por ejemplo, el avance tecnológico es un fin loable, pero ¿estamos realmente preparados para afrontar los dilemas morales en materia de inteligencia artificial?; ¿se han dado pasos suficientes para impedir que las grandes empresas tecnológicas controlen/espíen nuestras vidas a través de la acumulación masiva de datos con total impunidad? ${ }^{15}$; ¿pueden las empresas tecnológicas o del sector de la defensa realizar actos vinculados a las ciberamenazas o ciberguerra con afectación a la seguridad nacional ${ }^{16}$ y la seguridad humana? ${ }^{17}$

Vid. Transparency International. Índice de Percepción de la Corrupción 2019. Berlín, enero de 2020, p. 3, disponible en [https://www.proetica.org.pe/wp-content/uploads/2020/01/CPI2019_Report_ESWEB.pdf] (consulta: 7 de mayo de 2020).

13 La democracia en Colombia es calificada como "imperfecta" según el Índice Global de Democracia que elabora The Economist. The Economist Intelligence Unit. Democracy Index 2019. A year of democratic setbacks and popular protest. New York, 2020, p. 33, disponible en [https://www.in.gr/ wp-content/uploads/2020/01/Democracy-Index-2019.pdf] (consulta: 7 de julio de 2020).

14 En palabras de Krugman, "La desigualdad extrema sigue en aumento, y está envenenando a nuestra sociedad”. Paul Krugman. "Rich Man's Recovery”, The New York Times, September 12, 2013, disponible en [https:/www.nytimes.com/2013/09/13/opinion/krugman-rich-mans-recovery.html] (consulta: 27 de marzo de 2020).

15 En la década pasada descubrimos que había un espionaje masivo de las comunicaciones con fines supuestamente de seguridad nacional, pero también de espionaje industrial, de Estados Unidos, Reino Unido, Canadá, Australia y Nueva Zelanda a través del Proyecto Five Eyes. "Los cables de WikiLeaks han mostrado que el Departamento de Estado de EE. UU. ha estado particularmente activo a la hora de promover los intereses de Monsanto en el extranjero. Los cables filtrados aportan pruebas de que las embajadas y los consulados estadounidenses en Argentina, Alemania, Eslovaquia, España, Egipto y Sudáfrica promocionaron a Monsanto y sus productos en estos países." Nina Holland y Benjamin Sourice. El lobby de Monsanto: un ataque contra nosotros, nuestro planeta y nuestra democracia, Bruselas, Corporate Europe Observatory, 2016,p. 9, disponible en [https://corporateeurope.org/sites/ default/files/attachments/monsanto_es_v2_web.pdf] (consulta: 5 de mayo de 2020). Ya en 2019 hemos descubierto también que: "Microsoft admite que sus empleados escuchan una parte de las llamadas de Skype.Al igual que sucedía con Amazon y su asistente Alexa, Google y el Asistente y Apple con Siri". Europa Press. "Microsoft admite que sus empleados escuchan una parte de las llamadas de Skype", Público [en línea], 8 de agosto de 2019, disponible en [https://www.publico.es/ciencias/microsoftmicrosoft-admite-empleados-escuchan-parte-llamadas-skype.html] (consulta: 8 de agosto de 2019); Javier Cortés. "Protección de datos. El espionaje de los asistentes virtuales podría quedar impune", El País [en línea], 1. de agosto de 2019, disponible en [https://retina.elpais.com/retina/2019/08/01/ tendencias/1564646860_938931.html] (consulta: 18 de marzo de 2020).

16 Las empresas tecnológicas también han empezado a conquistar el espacio; por tanto, desempeñarán aún más si cabe actuaciones relevantes en el plano de la seguridad nacional y la seguridad humana. Por ejemplo, a finales de 2013 la empresa SpaceX lanzó desde California el cohete transportador Falcon 9 a GEO portando el satélite privado de comunicación SES-8. Empresas de este tipo deberían ser especialmente transparentes y éticas para prevenir conductas criminales, aquí el compliance debería ser obligatorio teniendo en cuenta la sensibilidad del sector en el que se opera y las magnas consecuencias que podrían derivarse si una empresa no es diligente. Sobre los desafíos del espacio, vid. Miguel Yagües Palazón. "Los desafíos medioambientales en el espacio ultraterrestre en el marco de la segunda era espacial", en Revista del Instituto Español de Estudios Estratégicos, n. ${ }^{\circ}$ 12, 2018, pp. 193-194.

17 En la reciente Estrategia Nacional de Ciberseguridad de España, el Presidente del Gobierno Pedro 
Con visión innovadora, los académicos debemos repensar fenómenos tradicionales que causan inestabilidad (terrorismo, crimen organizado, cambio climático, desigualdad, corrupción etc.) situando en el análisis ya no solo a los Estados o los individuos sino a las empresas. En consecuencia, el fenómeno del compliance será interesante para la mitigación de potenciales riesgos que emanarán desde tales organizaciones, teniendo presente que se está produciendo un tránsito desde el poder de la democracia al de la Lex Mercatoria, en el que las multinacionales son actores principales, lesionando, además, los derechos humanos ${ }^{18}$. En efecto, las multinacionales son una pieza clave dentro del tablero de la geopolítica, geoeconomía y geotecnología19.

Todo ello nos lleva a considerar que existe un consenso global en considerar a los entes corporativos, especialmente las multinacionales, sujetos que ocupan una posición nuclear dentro de nuestras sociedades. En consecuencia, es de vital importancia que el Estado, a través del derecho penal, proteja los bienes jurídicos ante la puesta en peligro de estos de la mano de la criminalidad corporativa, que, en buena medida, guarda relación con la falta de diligencia debida en su gestión empresarial.

En el ámbito económico y financiero, las acciones son hipercompetitivas ${ }^{20}$, por lo cual las políticas de ahorro de costes se llevan al extremo. Igualmente, se elaboran productos tóxicos y complejos fruto de la obstinación por obtener el máximo de los

Sánchez señala: "Las amenazas son cada vez más sofisticadas y complejas, y el ciberespacio es un ámbito sin fronteras ni demarcaciones jurisdiccionales claras, de débil regulación, donde resulta difícil la trazabilidad de las acciones delictivas llevadas a cabo por actores estatales y no estatales" (énfasis propio). Gobierno de España. Departamento de Seguridad Nacional. Estrategia Nacional de Ciberseguridad 2019. [Madrid], junio de 2019, p. 5, disponible en [https:/www.dsn.gob.es/es/ documento/estrategia-nacional-ciberseguridad-2019] (consulta: 4 de mayo de 2020).

18 Gonzalo Fernández Ortiz de Zárate. Alternativas al poder corporativo. 20 propuestas para una agenda de transición en disputa con las empresas transnacionales. Barcelona, Icaria, 2016, p. 45.

19 En estos momentos vemos cómo Estados Unidos se enfrenta a un gigante tecnológico como es Huawei en una batalla económica feroz con consecuencias diplomáticas (China vs. USA) en las que, a su vez, intervienen terceros actores como Google, Microsoft, Intel y Qualcomm. De fondo, proteccionismo económico, cuestiones vinculadas a la seguridad nacional en la creación y uso de las redes 5G. También la UE ha reaccionado con precaución ante la posibilidad de que dicha red quede en manos de compañías chinas. Ciberdelincuencia y ciberguerra son cuestiones fundamentales en las sociedades actuales. Jaume Masdeu. "La entrada de Huawei lleva a la UE a reforzar la seguridad del 5G", $L a$ Vanguardia [en línea], 26 de marzo de 2019, disponible en [https:/www.lavanguardia.com/tecnologia/20190326/461242978052/huawei-red-5g-ciberseguridad-ue.html] (consulta: 26 de marzo de 2019).

20 Deslocalización de empresas hacia países de Asia, Latinoamérica o Europa del Este con la intención de ahorrar costes de salarios, atenuar las condiciones de seguridad e higiene en el trabajo o limitar los derechos de huelga y sindicación. En los casos más graves derivaría hasta situaciones de esclavitud laboral. La orientación de la deslocalización también tendrá en cuenta qué países tienen una mayor debilidad económica e institucional para hacer cumplir las leyes, para en esa medida aprovecharlo en favor de la empresa. Julio Ballesteros Sánchez. "Criminalidad empresarial y Derecho penal: la responsabilidad penal de las personas jurídicas en el marco de la globalización y los llamados programas de cumplimiento efectivo", en AA. vv. Derecho Internacional Penal y Humanitario, Héctor Olásolo Alonso (coord.), Valencia, Tirant lo Blanch, 2016, pp. 241 y ss. 
beneficios. Todo ello incrementa la posibilidad de actos criminales en el sector empresarial. La guerra económica entre Estados y empresas acontece en la actualidad, a lo cual se suma un deterioro permanente del Estado del bienestar, en buena medida por los recursos que se detraen de la Hacienda Pública como resultado de la corrupción público-privada, el contrabando y la evasión fiscal a través de los paraísos fiscales por los que se escurren ingentes cantidades de impuestos no tributados ${ }^{21} \mathrm{y}$, también, se blanquea buena parte de las ganancias del crimen organizado.

Hoy en día hay conglomerados empresariales que cuentan con recursos económicos y humanos ingentes que pueden ser aprovechados, legítimamente, para la producción de bienes y servicios, o, contrariamente, puede hacerse un uso pernicioso de ellos y utilizarse para la comisión de actividades delictivas, lesionando bienes jurídicos en provecho propio. Ello no sería tan preocupante si nos enfrentáramos a pequeñas empresas, respecto a las cuales los cuerpos y fuerzas de seguridad del Estado y el Ministerio Público están capacitados para investigar de forma solvente. No obstante, se trata de organizaciones de grandes dimensiones cuyo impacto puede producir metástasis en el sistema.

El tamaño y la expansión de las grandes empresas son realmente sorprendentes. El valor de mercado de las diez empresas con mejores resultados en 2015 puede equipararse con el PIB de los 180 países con peor rendimiento macroeconómico ${ }^{22}$. Así mismo, de las 100 entidades económicas mundiales más grandes en 2016, solo 31 son Estados $^{23}$. Hace treinta años había 7000 multinacionales. Hoy hay más de $60.000^{[24]}$, que se despliegan a través de 450.000 filiales ${ }^{25}$. En palabras de Fernández, "Wal-Mart, Shell y Exxon Mobil tienen unos ingresos anuales superiores al PIB de países como Austria, Sudáfrica y Venezuela. Telefónica y Repsol, por su parte, manejan unos volúmenes de ventas que duplican el de Bolivia y el de Honduras, respectivamente"26.

En el pasado más reciente se ha podido observar desde la criminología y el derecho penal una serie de factores diversos que han facilitado la falta de persecución

21 En consecuencia, es de agradecer la aparición de la Norma UNE 19602 sobre Sistemas de Gestión de Compliance Tributario para dotar de pautas de actuación a las empresas en la prevención de irregularidades fiscales y tributarias.

22 Gonzalo Fernández Ortiz de Zárate. Alternativas al poder corporativo..., cit., pp. 47-48.

23 "10 biggest corporations make more money than most countries in the world combined", Global Justice Now, September 12, 2016, disponible en [https://www.globaljustice.org.uk/news/2016/ sep/12/10-biggest-corporations-make-more-money-most-countries-world-combined] (consulta: 27 de marzo de 2020).

24 Pedro Francés. Ética de los negocios, Bilbao, Desclée, 2004, p. 51.

25 Antonia Durán Ayago. "Sobre la responsabilidad de las empresas por violaciones graves de los derechos humanos en terceros países”, Anuario Español de Derecho Internacional Privado, n. ${ }^{\circ} 18$, 2018, p. 332.

26 Gonzalo Fernández Ortiz de Zárate. Alternativas al poder corporativo..., cit., p. 48. 
penal efectiva contra conductas criminales que se materializan desde los entornos corporativos. La prevención y la reacción ante la delincuencia económica han sido deficientes. Ello se debe en buena medida a las dificultades que ha tenido el Derecho penal tradicional para abordar situaciones complejas y profesionales producidas en entornos organizativos complejos ${ }^{27}$. En consecuencia, ha ido imponiéndose paulatinamente la necesidad, desde las garantías ${ }^{28}$, de incorporar la responsabilidad penal de las personas jurídicas. Hoy en día, como señala Sun Beale, la responsabilidad penal de las personas jurídicas debe considerarse "una parte necesaria de la ley de las naciones occidentales desarrolladas" 29 . Un límite a los excesos neoliberales y al creciente protagonismo de la delincuencia empresarial, sirviendo esta responsabilidad de línea Maginot ${ }^{30}$.

De acuerdo, por tanto, con De la Cuesta al afirmar que la empresa "no se considera como un ente abstracto sino como una institución social con personalidad jurídica propia -independientemente de la de sus partícipes-con derechos y obligaciones en cuanto tal"31. Algunos países, como Inglaterra, Estados Unidos, España, Portugal, Canadá, China, Japón, Australia, Suiza, Francia, Argentina, México, Ecuador y Chile, entre otros, han incorporado la responsabilidad penal de las personas jurídicas a sus ordenamientos jurídicos.

Lo cierto es que más allá de los debates dogmáticos sobre la responsabilidad de las personas jurídicas, que obviamente son necesarios, y su capacidad de acción y culpabilidad, etc., las empresas son sujetos que deben responder en multitud de legislaciones y, en algunas de ellas, el compliance sirve para graduar ${ }^{32}$ o determinar

27 Sobre la problemática para determinar la responsabilidad individual en el seno corporativo se recomienda Laura Zúñiga Rodríguez. Bases para un Modelo de Imputación de Responsabilidad Penal de las Personas Jurídicas, 3. a ed., Navarra, Aranzadi, 2009, p. 204.

28 Como perfectamente han señalado Balmaceda, Guerra y Juppet, "La respuesta político-criminal a este fenómeno de la criminalidad empresarial no pasa por abandonar los principios fundamentales del Derecho Penal, sino en mantener un equilibrio entre la configuración de esta nueva responsabilidad y los principios fundamentales de este Derecho". Gustavo Balmaceda Hoyos, Rodrigo Guerra Espinosa y María Juppet Ewing. Compliance. Visión general desde una perspectiva penal y comercial. Santiago de Chile, Thompson Reuters, 2019, p. 255.

29 Sara Sun Beale, "Una respuesta a las críticas a la responsabilidad penal corporativa", Anuario de Derecho Penal Económico y de la Empresa, n. ${ }^{\circ}$ 4, 2018, p. 53.

30 Steve Tombs y David Whyte. La empresa criminal. Barcelona, Icaria, 2016, p. 12.

31 Marta de la Cuesta González. "El porqué de la responsabilidad social corporativa", Boletín Económico de ICE $, \mathrm{n} .^{\circ} 2813,2004$, p. 46.

32 Por ejemplo, en el año 1991 en los Estados Unidos se aprobaban las Directrices para la determinación individual de la pena (Sentencing Guidelines). Para Nieto, en los Estados Unidos desde 1991 "las corporaciones que adopten programas de cumplimiento, esto es, medidas de prevención de determinados delitos o colaboren en su esclarecimiento, reciben como premio sanciones menores que aquellas que no lo hagan”. Adán Nieto Martín. "De la ética pública al public compliance: sobre la prevención de la corrupción en las administraciones públicas”, en AA. VV. Derecho, confianza y democracia. Jerónimo Betegón y Juan Ramón de Páramo (coords.), Albacete, Bomarzo, 2013, p. 106. 
su culpabilidad penal. En efecto, el compliance puede tener efecto como atenuante o eximente. Igualmente, los programas de cumplimiento son obligatorios para poder participar en determinados sectores regulados ${ }^{33}$ y son cada vez más necesarios para poder recibir subvenciones, contratar con el Estado ${ }^{34}$ o recibir menor tiempo de penalización ${ }^{35}$ en los procedimientos sancionatorios de listas negras del Banco Mundial ${ }^{36}$. En definitiva, la imputación penal de las personas jurídicas y la utilidad de los programas de cumplimiento son ya una realidad.

Como es sabido, el término compliance guarda relación con la expresión inglesa to comply with (the law), lo cual podría traducirse del siguiente modo: cumplir con (el Derecho $)^{37}$. En este sentido, compliance penal equivaldría a aquella situación en la que se están cumpliendo con las normas penales. Ahonda en ello Reaño al señalar que el compliance penal "significa autovigilancia y fomento de una mentalidad corporativa de fidelidad al Derecho" 38 . Los programas de cumplimiento se conforman a través de una serie de exigencias de diversa naturaleza que han sido señalados por la doctrina. En este sentido, serán elementos indispensables del sistema de cumplimiento aquellos que permiten: identificar mediante un mapa de riesgos aquellas actividades en cuyo ámbito puedan ser cometidos delitos que son objeto de persecución contra las personas jurídicas; establecer protocolos que concreten el proceso ${ }^{39}$ de formación

33 Por ejemplo, en el sector bancario y financiero español, la Ley 10/2010, del 28 de abril, de Prevención de Blanqueo de Capitales y de la Financiación del Terrorismo y Real Decreto 304/2014, del 5 de mayo, por el que se aprueba el Reglamento de la Ley 10/2010, del 28 de abril, de prevención del blanqueo de capitales y de la financiación del terrorismo.

34 El artículo 24 de la Ley 27.401, de Régimen de Responsabilidad Penal, de 2017 (Argentina), señala que los programas de integridad son obligatorios para aquellas empresas que quieran contratar con el Estado. Estos programas pueden ayudar a mitigar los siguientes problemas: fraccionamiento de contratos; ausencia de transparencia; excesos en la utilización del procedimiento negociado sin publicidad; sobrecostes injustificados; existencia de pliegos de contratación a medida para favorecer a una empresa en particular; deficitarios procesos de control sobre la ejecución de los contratos; existencia de conflictos de intereses no detectados; adjudicaciones directas injustificadas etc.

35 Adán Nieto Martín. "De la ética pública al public compliance...”, cit., p. 106.

36 Por ejemplo, el Banco Mundial inhabilitará desde agosto de 2020 a una empresa de construcción de Colombia durante 18 meses por haber realizado conductas indebidas relacionadas con un proyecto de control de inundaciones financiado por el Banco de Bogotá. Harry Cassin. "World Bank announces two debarments for "fraudulent practices", The FCPA blog, 19 de agosto de 2020, disponible en [https://fcpablog.com/2020/08/19/world-bank-announces-two-debarments-for-fraudulent-practices/] (consulta: 19 de agosto 2020).

37 Dennis Bock. "Compliance y deberes de vigilancia en la empresa", en AA. vV. Compliance y teoría del Derecho penal. Madrid, Marcial Pons, 2013, p. 107.

38 José Leandro Reaño Peschiera. "La utilidad de los programas de criminal compliance para las empresas que operan en Perú", Revista de Derecho Themis, n. ${ }^{\circ}$ 68, 2015, p. 142.

39 Para Gómez, serán elementos que deben tener en cuenta los protocolos de toma de decisiones los siguientes: "Propuesta. Justificación. Informe técnico. Informe jurídico. Valoración del riesgo penal. Recomendación favorable o desfavorable. Deliberación. Votación con mayoría reforzada. Advertencia en el acta". Paula Gómez Doñate. "Modelo de prevención y control", en AA. VV. Practicum Compliance 2018, Xavier Ribas (dir.), Navarra, Aranzadi, 2018, p. 70. 
de la voluntad de la persona jurídica ${ }^{40}$, adopción de decisiones y ejecución de ellas; disponer de recursos financieros suficientes ${ }^{41}$ para implementar, mantener y revisar el programa; imponer la obligación de informar de posibles riesgos e incumplimientos al organismo encargado de vigilar el funcionamiento y observancia del programa (whistleblowing); establecer un sistema disciplinario que sancione proporcionadamente el incumplimiento del programa; y verificar periódicamente el programa ${ }^{42}$, modificando éste cuando se detecten infracciones o nuevos riesgos, consecuencia de cambios en la organización de la empresa o de la apertura de nuevas líneas de negocio.

En cualquier caso, los elementos necesarios para elaborar un programa de cumplimiento están estandarizados internacionalmente, por lo tanto, dichos elementos serán herramientas útiles para la mitigación de riesgos en otros fenómenos de naturaleza no estrictamente penal (refuerzo de las administraciones públicas y del funcionamiento de los partidos políticos, logro de la seguridad humana y situaciones de afectación a la seguridad nacional) que a continuación se señalan.

\section{2. ÁMBITOS DE EXPANSIÓN DEL “COMPLIANCE”}

Los programas de cumplimiento son una herramienta que permite, desde la eficacia de cada uno de sus elementos, optimizar el funcionamiento de las organizaciones a partir de la mejora de cada uno de sus procesos internos, logrando, a su vez, un incremento del buen gobierno y un menor riesgo legal. Además, entendiendo el objetivo de cada uno de los elementos que conforman los programas se puede pronosticar que contribuyen en la consecución de avances sustantivos en otros ámbitos.

Por ejemplo, si un partido político se rige por adecuados procedimientos de formación de la voluntad es posible que ello provoque una mayor democracia interna que redundará en un mejor gobierno. En otro plano, si una empresa nacional del sector de la defensa implementa canales de denuncia internos podrá detectar anticipadamente si alguien de la empresa está robando secretos industriales, lo cual supondría ya no solo un problema económico y de competitividad de dicha empresa, sino una amenaza a la seguridad nacional, si se trata de una tecnología prioritaria para la defensa de la nación.

40 En la sentencia del Tribunal Constitucional n. ${ }^{\circ}$ 246/1991 del 19 de diciembre se señala sobre las personas jurídicas que "falta en ellos el elemento volitivo en sentido estricto, pero no la capacidad de infringir las normas a las que están sometidos”. Por ello, es más interesante en términos de cumplimiento incidir en las políticas que rigen en la empresa a la hora de enfrentar deliberaciones y procesos de toma de decisiones para entender qué es lo que desea la empresa que ocurra, lo que de alguna forma expresaría la voluntad de la organización.

41 Adán Nieto Martín y Beatriz García Moreno (coords.). Guía para la prevención de la corrupción en las Administraciones Públicas de Castilla-La Mancha. Cuenca, Ediciones Universidad de CastillaLa Mancha, 2018, p. 26.

42 Neus Ruiz-Lluch Manils. "Manual de cumplimiento: elementos esenciales", en AA. vv. Guía de implementación de compliance para pymes. Madrid, World Compliance Association, 2019, p. 55. 
Me atrevo a afirmar que el nuevo y mejor aporte que pueden hacer los programas de cumplimiento está orientado a la consecución de los derechos humanos, la seguridad humana, la seguridad nacional y el fortalecimiento y regeneración de las instituciones en democracia. A ello dedicaremos la siguiente sección.

\subsection{Derechos humanos, seguridad y democracia}

La protección y salvaguarda de los derechos humanos debe ser una prioridad para los Estados. En particular, España, al igual que otros países, ha asumido numerosos compromisos internacionales orientados al amparo y promoción de tales derechos ${ }^{43}$. Por esa razón, debe orientar su marco legislativo e institucional a fin de poder cumplir con tales compromisos. Así mismo, el Estado debe controlar que las empresas tampoco vulneran los citados derechos.

Resulta intolerable que bien entrado el siglo XXI aún se sigan produciendo violaciones masivas a los derechos humanos por parte de las empresas. Estas organizaciones controlan con rigor la calidad de sus productos y meticulosamente los costes de producción, sin embargo, los esfuerzos para la salvaguarda de tales derechos han sido mínimos. Como señala Demetrio Crespo, "hay que hacer un esfuerzo muy serio de reflexión acerca de los instrumentos jurídicos adecuados, incluyendo al Derecho penal internacional, para prevenir y sancionar las terribles consecuencias que aquellas provocan" 44 .

En esta línea de pensamiento, algunos países han legislado de forma contundente para prevenir, desde un management empresarial responsable, la aparición de situaciones vulneradoras de los derechos humanos. Ese es el caso de Francia pero no el

43 Convenio Europeo para la Protección de los Derechos Humanos y las Libertades Fundamentales; Carta de Derechos Fundamentales de la Unión Europea; Pacto Internacional de Derechos Civiles y Políticos y sus Protocolos Facultativos; Pacto Internacional de Derechos Económicos, Sociales y Culturales y su Protocolo Facultativo; Convención Internacional sobre la Eliminación de todas las Formas de Discriminación Racial; Convención Internacional sobre la Eliminación de todas las Formas de Discriminación contra la Mujer; Convención contra la Tortura y otros Tratos o Penas Crueles, Inhumanos o Degradantes y su Protocolo Facultativo; Convención sobre los Derechos del Niño y sus tres Protocolos Facultativos; Convención sobre los Derechos de las Personas con Discapacidad; Convención Internacional para la Protección de todas las Personas contra las Desapariciones Forzadas. Organización Internacional del Trabajo (OIT): Convenio $n .{ }^{\circ} 29$ sobre el trabajo forzoso u obligatorio; Convenio n. ${ }^{\circ} 87$ sobre la libertad sindical y la protección del derecho de sindicación; Convenio n. ${ }^{\circ} 98$ sobre el derecho de sindicación y de negociación colectiva - Convenio n. ${ }^{\circ} 100$ sobre la igualdad de remuneración; Convenio n. ${ }^{\circ} 105$ sobre la abolición del trabajo forzoso; Convenio n. ${ }^{\circ} 111$ sobe la discriminación (empleo y ocupación); Convenio n. ${ }^{\circ} 138$ sobre la edad mínima de admisión al empleo; Convenio n. ${ }^{\circ} 182$ sobre la prohibición de las peores formas de trabajo infantil y la acción inmediata para su eliminación. Convenio n. ${ }^{\circ} 169$ de la OIT sobre Pueblos Indígenas.

44 Eduardo Demetrio Crespo. "Vulneración de Derechos Humanos por empresas multinacionales: ¿De un Derecho penal económico transnacional a un Derecho penal internacional económico?”, en AA. Vv. Derecho penal económico y derechos humanos, Eduardo Demetrio Crespo y Adán Nieto Martín (dirs.), Valencia, Tirant lo Blanch, 2018, p. 23. 
de España, que simplemente ha elaborado un Plan de Acción Nacional de Empresas y Derechos Humanos $(2017)^{45}$ que apenas ha tenido repercusión. Por el contrario, Francia ha realizado un esfuerzo normativo importante que supone un verdadero y real avance.

La Loi n. ${ }^{\circ}$ 2017-399, de 2017, relativa al deber de vigilancia de las empresas matrices sobre sus filiales, impone a las corporaciones francesas un deber de control sobre sus filiales en terceros países, que se materializa en una serie de directrices de diligencia debida que toma forma a través de un programa de cumplimiento de derechos humanos, también llamado "Plan de Vigilancia". Es decir, la empresa matriz controlará a sus filiales y proveedores en el extranjero para evitar que lesionen derechos humanos, libertades fundamentales, la salud y seguridad de las personas y el medio ambiente.

Aquellas corporaciones con sede social en Francia y que cuenten (al cierre de dos ejercicios financieros consecutivos) con 5000 empleados o bien 10.000 trabajadores distribuidos por terceros países deberán implementar un programa de vigilancia con las siguientes características: existencia de un mapa de riesgos; diseño y ejecución de procedimientos de análisis de filiales, proveedores y empresas subcontratadas orientados a la detección y control de riesgos; realización de esfuerzos para mitigar las posibilidades la puesta en peligro de los derechos humanos; implementación de mecanismos de alerta temprana en la organización con participación de los representantes sindicales de la empresa; realización de monitoreo y evaluación ${ }^{46}$ del programa de vigilancia para comprobar su nivel de eficacia ${ }^{47}$.

En cuanto a España, desde el Plan de Acción Nacional de Empresas y Derechos Humanos del Gobierno de España de 2017 se sostiene que las empresas deben orientar sus protocolos, manuales, códigos, procedimientos y prácticas, con el que se ejerza "diligencia debida en materia de derechos humanos para identificar, prevenir, mitigar y rendir cuentas de cómo abordan su impacto sobre los derechos humanos"48.

45 También otros países han elaborado documentos estratégicos de la misma naturaleza. Colombia, Reino Unido, Holanda, Dinamarca, Finlandia, Lituania, Suecia, Noruega, Suiza, Italia, Estados Unidos y Alemania.

46 Todo lo que no es susceptible de medición o evaluable corre el riesgo de no ser revisado de forma periódica o no ser eficaz. Por ello, la elaboración de indicadores puede considerarse una medida idónea para dar seguimiento a los logros conseguidos con el programa de cumplimiento. Estos indicadores deben venir claramente definidos y apoyarse, según sea el proceso, en datos cuantitativos o cualitativos. Real Academia de Ciencias Económicas y Financieras. Empresas a favor de las personas: el camino hacia el respeto de los derechos humanos. Barcelona, Ministerio de Educación Cultura y Deporte, 2016, p. 40.

47 Antonia Durán Ayago. "Sobre la responsabilidad de las empresas...”, cit., pp. 335-336. En Francia la Loi n. ${ }^{\circ}$ 2017-399, relative au devoir de vigilance des sociétés mères et des entreprises donneuses d'ordre, du 2017.

48 Gobierno de España. Plan de Acción Nacional de Empresas y Derechos Humanos. [Madrid], 2017, pp. 1-23, disponible en [http://www.exteriores.gob.es/Portal/es/PoliticaExteriorCooperacion/ 
Por ello, puede afirmarse que el ejercicio de la diligencia debida, junto con las orientaciones recomendadas, debe desembocar, sin ninguna duda, en la implementación del sistema de cumplimiento normativo, como herramienta con la cual se canalizará la realización de las exigencias que señala el Plan de Acción Nacional. El inconveniente existente en este punto es que la falta de cumplimiento normativo, como tal, no implica, al menos en la actualidad, ningún tipo de sanción jurídico-penal para la persona jurídica. Esto es inaceptable. En efecto, nos movemos en el terreno de la responsabilidad social corporativa de naturaleza ética pero inexistente presión jurídica. En definitiva, el Plan de Acción Nacional "es un documento no vinculante, programático y sin medidas efectivas protectoras" 49 .

Así mismo, en lo que se quiere incidir en este texto es en el hecho que tomar como modelo los elementos de compliance recogidos en el artículo 31 bis $\mathrm{CP}$ sería óptimo desde un perspectiva de gestión corporativa que quiera facilitar el logro de las autoexigencias éticas asumidas por la empresa. Desde dicho modelo de cumplimiento se podría satisfacer la máxima de Proteger, respetar y remediar de Naciones Unidas en materia de diligencia debida ${ }^{50}$. Por ejemplo, si desde Naciones Unidas se señala: "Las empresas deberían detectar y solucionar los agravios en una fase temprana, antes de que se intensifiquen" 51 , un buen medio de detección sería un canal interno de denuncias que proteja al denunciante frente a represalias, dando también participación en la elaboración del programa a los stakeholder $s^{52}$. Además, se deberán reformar los procesos que dieron lugar al menoscabo de los derechos humanos (para que no vuelva a producirse el daño), actualizar el programa de cumplimiento y resarcir a la víctima. De esta forma se satisfarían las exigencias vinculadas al concepto remediar.

DerechosHumanos/Documents/Plan\%20de\%20Acci\%C3\%B3n\%20Nacional\%20de\%20Empresas\%20y\%20Derechos\%20Humanos.pdf] (consulta: 7 de marzo de 2020).

49 Ana Isabel Pérez Cepeda. "Hacia el fin de la impunidad de las empresas transnacionales por la violación de los Derechos Humanos", en Revista Penal, n. ${ }^{\circ}$ 44, 2019, p. 134.

50 "El cumplimiento de la obligación de respetar los derechos humanos requiere la debida diligencia. Este concepto describe las medidas que debe tomar una empresa para tener conocimiento, prevenir y responder a los efectos negativos sobre los derechos humanos. En las empresas ya existen habitualmente procesos comparables porque muchos países están jurídicamente obligados a tener sistemas de información y control para evaluar y gestionar los riesgos financieros y conexos" (énfasis propio). Estas medidas, indeterminadas en dicho documento, serían satisfechas con un programa de cumplimiento similar al detallado en el CP. Consejo de Derechos Humanos. Asamblea General de Naciones Unidas. Proteger, respetar y remediar: un marco para las actividades empresariales y los derechos humanos. Informe A/HRC/8/5, 7 de abril de 2008, par. 56, p. 18, disponible en [https://observatoriorsc.org/wpcontent/uploads/2013/11/Proteger_respetar_remediar_abril2008.pdf] (consulta: 2 de marzo de 2020).

51 Ibídem, p. 26.

52 Debemos tener presente que la información de los grupos de interés puede llegarnos por diversas vías: quejas y reclamaciones en las oficinas, mensajes en redes sociales, líneas telefónicas de atención al cliente, correos electrónicos, informes de ONG, encuentros en asociaciones de vecinos, etc. Todo ello será información valiosa para la gestión eficiente de la organización, pues permitirá conocer mejor el entorno y los riesgos que pueden presentarse. De esta forma podemos anticipar escenarios minimizando riesgos o creando valor social. 
Como ha podido observarse, tanto en Francia, a partir de la Loi n. ${ }^{\circ}$ 2017-399, como en España, mediante las recomendaciones del Plan de Acción Nacional de Empresas y Derechos Humanos, se intenta fortalecer el marco nacional regulatorio que protege los derechos humanos. De forma complementaria podrían lograrse mejores resultados en la protección de las personas si vinculamos a la empresa con el concepto de Naciones Unidas de "seguridad humana". Para ello debemos, en primer lugar, entender el alcance y contenido de dicho concepto y cómo, mediante la delincuencia empresarial, se puede deteriorar la seguridad humana. A sensu contrario, desde la prevención de la delincuencia empresarial se contribuye a la seguridad de forma integral.

En palabras de la Comisión sobre seguridad humana de las Naciones Unidas, atender a la seguridad humana consiste en

proteger la esencia vital de todas las vidas humanas de una forma que realce las libertades humanas y la plena realización del ser humano. Seguridad humana significa proteger las libertades fundamentales: libertades que constituyen la esencia de la vida. Significa proteger al ser humano contra las situaciones y las amenazas críticas (graves) y omnipresentes (generalizadas). Significa utilizar procesos que se basan en la fortaleza y las aspiraciones del ser humano. Significa la creación de sistemas políticos, sociales, medioambientales y culturales que, en su conjunto, brinden al ser humano las piedras angulares de la supervivencia, los medios de vida y la dignidad ${ }^{53}$.

En la doctrina podemos encontrar dos corrientes sobre el tema, un concepto restrictivo de seguridad humana (freedom from fear) afincado en Canadá, Suecia o Noruega y otro más extenso, defendido en Japón (freedom from want). La primera corriente solo entiende como causa de inseguridad aquellas que implican violencia física (por ejemplo, conflictos armados). En cambio, la segunda línea de pensamiento entiende que la seguridad humana es algo más complejo y, por lo tanto, debe incluir factores económicos, alimentarios, sanitarios, medioambientales, personales, comunitarios, políticos e incluso cuestiones de género ${ }^{54}$. Esta segunda vertiente es sobre la que

53 Commission on Human Security. Human Security Now, New York, 2003, p. 4, disponible en [https:// reliefweb.int/sites/reliefweb.int/files/resources/91BAEEDBA50C6907C1256D19006A9353-chs-securitymay03.pdf] (consulta: 20 de marzo de 2020).

54 La perspectiva de género es necesaria y debe ser tenida muy en cuenta en la actualidad. Afirma el World Economic Forum que "la brecha mundial de igualdad de género en salud, educación, política y lugar de trabajo se amplió por primera vez desde que iniciamos el seguimiento en el 2006, mientras que una serie de casos de alto perfil resaltan los niveles endémicos continuos de acoso sexual, tanto en el lugar de trabajo como en la sociedad en general". Además, desde la perspectiva de derechos humanos, si por ejemplo, una empresa no permite a una mujer volver a su puesto de trabajo después de su permiso de maternidad se estaría vulnerando el Derecho a la no discriminación. En consecuencia, los programas de cumplimiento en las organizaciones deben incorporar mecanismos de prevención y protección de las mujeres, lo que incluye, protocolos antiacoso sexual o políticas de igualdad contribuirían a la seguridad humana y los derechos humanos. World Economic Forum. Informe de riesgos 
se puede asentar la relación entre empresa y seguridad humana propuesta en este trabajo, con el fin de fortalecer la respuesta al desafío de la criminalidad empresarial. Humanizar la globalización exige incrementar la respuesta penal nacional e internacional contra las empresas y propiciar entornos que garanticen la seguridad humana de los ciudadanos.

El mundo actual se caracteriza por ser un lugar inseguro, que se encuentra bajo la amenaza de múltiples fenómenos: crisis económicas prolongadas y cíclicas, cambio climático favorecido por la contaminación y los delitos ambientales, conflictos violentos entre Estados y actores no estatales, epidemias, ausencia de prosperidad y erosión en los Estados de derecho como consecuencia de la corrupción, entre otros factores. En ese contexto nace el concepto de seguridad humana para favorecer e impulsar el desarrollo de las sociedades y garantizar a los individuos su libertad, dignidad e integridad física, y las condiciones básicas necesarias para todo ser humano ${ }^{55}$. Es necesario considerar que las citadas amenazas se entrelazan y retroalimentan creciendo exponencialmente, sin detenerse ante las fronteras. Se trata, por lo tanto, de problemas globales que deben implicar a todos los actores (Estados, organismos internacionales, sociedad civil y empresas).

Los Estados ya no son los únicos actores en la esfera internacional. También las multinacionales tienen un papel que cumplir. Bien es cierto, como señala Rojas, que los Estados "han perdido su poder monopólico sobre las comunicaciones, el desarrollo tecnológico, las finanzas, las inversiones, las migraciones internacionales y sobre el comercio" 56 , por tanto, las empresas, algo (o mucho) tendrán que hacer en pos de la sociedad. Al respecto, Naciones Unidas afirma: "[L] a sociedad civil, las organizaciones regionales y el sector privado son necesarios para poder abordar problemas de muy distinta naturaleza" 57 . En efecto, si las amenazas están interrelacionadas y, además, son difusas, una respuesta únicamente estatal no sería suficiente para su mitigación ${ }^{58}$.

mundiales 2018, 13. a ed., Ginebra, 2018, p. 10, disponible en [https://www.mmc.com/content/dam/ mmc-web/Global-Risk-Center/Files/the-global-risks-report-2018-es.pdf] (consulta: 7 de julio de 2020); Real Academia de Ciencias Económicas y Financieras. Empresas a favor de las personas..., cit., p. 21.

55 "Toda persona tiene derecho a la vida, la libertad y la seguridad”. Declaración Universal de Derechos Humanos, Resolución 217 A (III), del 10 de diciembre de 1948.

56 Francisco Rojas Aravena y Andrea Álvarez Marín. "Seguridad Humana. Un estado del arte”, en AA. Vv. Seguridad Humana: nuevos enfoques. Francisco Rojas Aravena (ed.), San José de Costa Rica, Flacso, 2012, p. 12.

57 Asamblea General de Naciones Unidas. Seguimiento de la resolución 66/290 de la Asamblea General sobre seguridad humana. Informe del Secretario General A/68/685, 23 de diciembre de 2013, parágrafo 36, p. 10, disponible en [https://undocs.org/pdf?symbol=es/A/68/685] (consulta: 2 de marzo de 2020).

58 Miguel Ángel Pérez Franco. "Seguridad humana: ¿el complemento perfecto para nuestras estrategias de seguridad?”, Revista del Instituto Español de Estudios Estratégicos, Documento de Opinión n. ${ }^{\circ} 118,2016$, p. 14 . 
El enfoque necesario para afrontar las amenazas previamente mencionadas es, fundamentalmente, preventivo, pues, como ha señalado Naciones Unidas, este enfoque

Ayuda a desentrañar las causas profundas de las vulnerabilidades, presta especial atención a los riesgos incipientes y hace hincapié en la intervención temprana. La prevención refuerza la capacidad local para crear resiliencia y promueve soluciones que consolidan la cohesión social y hacen valer el respeto de los derechos humanos y la dignidad ${ }^{59}$.

En el cuadro n. ${ }^{\circ} 1$ se exponen los siete tipos de seguridad que componen la seguridad humana. Cada uno de estos tipos de seguridad se corresponde con distintos problemas sociales, laborales y ambientales expuestos en la segunda columna. Finalmente, la tercera columna ofrece un ejemplo de conducta corporativa que deteriora el contenido de la respectiva seguridad.

Cuadro n. ${ }^{\circ}$ 1. Tipos de seguridad humana, contenido y delitos empresariales

\begin{tabular}{|l|l|l|}
\hline \multicolumn{1}{|c|}{ Seguridad } & \multicolumn{1}{|c|}{ Contenido } & \multicolumn{1}{c|}{ Vinculación empresarial (ejemplos) } \\
\hline Económica & $\begin{array}{l}\text { Pobreza, desempleo } \\
\text { o precariedad laboral. }\end{array}$ & $\begin{array}{l}\text { Corrupción público-privada. } \\
\text { Fraudes masivos. } \\
\text { Por ejemplo, Enron }\end{array}$ \\
\hline Alimentaria o Bernard Madoff & 62. \\
\hline & Sed y hambre. & $\begin{array}{l}\text { Estrés hídrico provocado por la sobreexplotación } \\
\text { industrial. } \\
\text { Por ejemplo, caso Coca Cola en El Salvador }{ }^{63} .\end{array}$ \\
\hline
\end{tabular}

(continúa)

59 Fondo Fiduciario de las Naciones Unidas para la Seguridad Humana. "Qué es la seguridad humana?" [en línea], 28 de noviembre de 2017, disponible en [https://www.un.org/humansecurity/es/what-ishuman-security/] (consulta: 8 de mayo de 2020).

60 Como consecuencia del caso Odebrecht, la compañía ha despedido a 100.000 empleados en dos años. Ha pasado de tener 180.000 empleados a 80.000 .

61 Provocó estafas por valor de 60.000 millones de dólares. Ampliamente sobre este caso, Kathleen Brickey. "Enron's Legacy”, Buffalo Criminal Law Review, vol. 8, n. 2 2, 2004, pp. 225 y ss.

62 Supuso un fraude de cerca de 49.000 millones de euros e hizo temblar al sector financiero globalmente.

63 "El uso de un acuífero para hacer Coca-Cola amenaza el agua de 30.000 personas en El Salvador. La sobreexplotación de un acuífero de una embotelladora subcontratada por Coca-Cola amenaza el acceso al agua de un municipio". Maribel Hernández. "El uso de un acuífero para hacer Coca-Cola amenaza el agua de 30.000 personas en El Salvador”, El Diario.es [en línea], 15 de junio de 2015, disponible en [https://www.eldiario.es/desalambre/Agua-El_Salvador-Coca_Cola-Medio_Ambiente_0_397560950.html] (consulta: 27 de marzo de 2020). El informe de Alianza por la Solidaridad documenta "las amenazas al derecho humano al agua de 30.000 personas cuando los intereses de una multinacional prevalecen sobre los derechos de las personas, priorizando el uso industrial frente al 


\begin{tabular}{|l|l|l|}
\hline \multicolumn{1}{|c|}{ Seguridad } & \multicolumn{1}{|c|}{ Contenido } & \multicolumn{1}{c|}{ Vinculación empresarial (ejemplos) } \\
\hline Salud & $\begin{array}{l}\text { Enfermedades infeccio- } \\
\text { sas } \\
\text { de asistencia médica. }\end{array}$ & Sobreprecios en los medicamentos ${ }^{65}$. \\
\hline Medioambiental & $\begin{array}{l}\text { Degradación ambiental } \\
\text { (deforestación, minería } \\
\text { ilegal), cambio climático } \\
\text { y contaminación. }\end{array}$ & $\begin{array}{l}\text { Delitos ambientales. } \\
\text { Falta de políticas ambientales. } \\
\text { Complicidad con la minería ilegal. } \\
\text { Casos emblemáticos: Volkswagen } \\
\text { y la ganadería extensiva en el Amazonas }{ }^{68} .\end{array}$ \\
\hline
\end{tabular}

(continúa)

agua para consumo humano". Alianza por la Solidaridad. El caso Nejapa, Informe. [El Salvador], junio de 2015, p. 3, disponible en [http://www.alianzaporlasolidaridad.org/especiales/tierrra/pdf/ Informe_CocaCola_Salvador.pdf] (consulta: 16 de julio de 2019).

64 No se escapa que los grandes laboratorios y farmacéuticas realizan experimentación científica con virus y bacterias. En sentido negativo, pueden darse fugas de sus instalaciones, lo cual provocaría epidemias o, por el contrario y en sentido positivo, pueden lograr vacunas y remedios médicos que las mitiguen.

65 Mediante una agresiva política de adquisiciones Valeant, farmacéutica de Estados Unidos, adquirió más de cien empresas del sector, recortando en ellas el 97\% del gasto en investigación e incrementando, especialmente en medicamentos que había cierto monopolio, el precio de los medicamentos en el $78 \%$. Mediante estas prácticas, que no ilegales pero sí contrarias a la ética, se dejaba a muchos pacientes sin posibilidad de medicarse, logró que el valor de la compañía pasara de 2300 millones de dólares a 78.000. Erin Lee Carr (dir.). "Venta en corto y farmacéuticas", Documental: Dirty Money/ Netflix, temporada 1, episodio 3, 26 de enero de 2018. También George señala: "La diferencia entre el precio al consumidor y los costes de producción es tan enorme que los medicamentos en EE. UU. podrían venderse por una décima parte de su precio”. Susan George. Los usurpadores..., cit., p. 127.

66 El fraude de Volkswagen consistía en trucar los motores para eludir en los controles sobre los niveles de óxido de nitrógeno (NOx) y poder contaminar hasta cuarenta veces más de lo permitido. Once millones de vehículos en todo el mundo fueron adulterados. United States-Department of Justice, Office of Public Affairs. "Volkswagen AG Agrees to Plead Guilty and Pay \$4.3 Billion in Criminal and Civil Penalties; Six Volkswagen Executives and Employees are Indicted in Connection with Conspiracy to Cheat U. S. Emissions Tests". Justice News [en línea], January 11, 2017, disponible en [https://www.justice.gov/opa/pr/volkswagen-ag-agrees-plead-guilty-and-pay-43-billion-criminaland-civil-penalties-six] (consulta: 27 de marzo de 2020).

67 Como consecuencia de las deficiencias de control en la plataforma Deepwater Horizon, empresa subcontratada por la petrolera BP, se produjo un inmenso vertido de petróleo en el Golfo de México que dio lugar a un desastre ambiental y la muerte de trece personas. "Los trabajadores de la plataforma se habían percatado de los fallos de seguridad y las malas prácticas de la plataforma y, sin embargo, no denunciaron la situación por temor a represalias en el entorno laboral." Clara Gutiérrez Muñoz. El estatuto de la responsabilidad penal de las personas jurídicas: aspectos de Derecho material, tesis doctoral, Universidad Autónoma de Barcelona, 2016, pp. 244-245.

68 "Hasta el 80\% de la desforestación en los países amazónicos se debe a la ganadería, lo que sugiere que las presiones sobre los sistemas ambientales y agrícolas se intensificarán a medida que aumente la población mundial y se incremente la demanda de carne." World Economic Forum. Informe de riesgos mundiales $2018 \ldots$, cit., p. 13. 


\begin{tabular}{|c|c|c|}
\hline Seguridad & Contenido & Vinculación empresarial (ejemplos) \\
\hline Personal & $\begin{array}{l}\text { Violencia física, } \\
\text { terrorismo, trabajo y } \\
\text { explotación infantil. }\end{array}$ & $\begin{array}{l}\text { Actuación desproporcionada de empresas } \\
\text { de seguridad y defensa en Estados de débil } \\
\text { cultura de legalidad }{ }^{69} \text {. } \\
\text { Financiamiento o complicidad con el terrorismo } \\
\text { o el crimen organizado. } \\
\text { Cadenas de proveedores sin due diligence. } \\
\text { Por ejemplo: } \text { HSBC }^{70} \text { o Lafarge }\end{array}$ \\
\hline Política & $\begin{array}{l}\text { Autoritarismo, deterioro } \\
\text { de la democracia }{ }^{72} \text {, viola- } \\
\text { ción de derechos huma- } \\
\text { nos, censura, represión } \\
\text { y persecución. }\end{array}$ & $\begin{array}{l}\text { Financiación ilegal de partidos políticos } \\
\text { y corrupción. } \\
\text { Apoyo a gobiernos dictatoriales }{ }^{73} \text {. } \\
\text { Por ejemplo, caso Petrobras }{ }^{74} \text {. }\end{array}$ \\
\hline
\end{tabular}

(continúa)

69 Executive Outcomes realizó en 1996 acciones ofensivas de fuerza letal, previo encargo del Gobierno de Sierra Leona, para combatir al Frente Unido Revolucionario a cambio de grandes sumas de dinero y concesiones en las minas de diamantes (de sangre). Mario Laborie Iglesias. "La controvertida contribución de las empresas militares y de seguridad privadas EMSP a la resolución de conflictos", Cuadernos de Estrategia, n. ${ }^{\circ}$ 147, 2010, p. 103.

70 La entidad no tenía ningún control efectivo sobre sus clientes en México, llegando a la negligencia generalizada en su funcionamiento al realizar operaciones para personas y empresas que estaban dentro de la Lista OFAC, algunas vinculadas, incluso, al cartel de Sinaloa, el cartel del Norte del Valle y el grupo terrorista Hezbolá. United States District Court. The Eastern District of New York. HSBC's Deferred Prosecution Agreement, Statement of Facts. Case 1:12-cr-00763-ILG Document 3-3. (United States of America vs. HSBC Bank USA, N. A. and HSBC Holdings PLC). December 11, 2012, disponible en [https://www.justice.gov/sites/default/files/opa/legacy/2012/12/11/dpa-attachment-a. pdf] (consulta: 27 de marzo de 2020); Kristi Jacobson (dir.). "El banco de los carteles", documental: Dirty Money/Netflix, temporada 1, episodio 4, 26 de enero de 2018.

71 En el grupo cementero franco-suizo Lafarge Holcim Eric Olsen, seis de sus altos directivos, están acusados en Francia por financiar supuestamente el terrorismo internacional al haber adquirido petróleo del Estado Islámico pese a las órdenes de embargo impuestas por la UE y por abonar mensualmente dinero al grupo terrorista para poder mantener abierta su fábrica en Siria. "Lafarge cement giant in terrorist funding probe", BBC News Business [en línea], June 28, 2018, disponible en [https://www. bbc.com/news/business-44643703] (consulta: 27 de marzo de 2020).

72 Las consecuencias de la delincuencia empresarial en la política pueden ser devastadoras. En Perú, las más altas instancias han estado implicadas en el caso Odebrecht provocando un auténtico tsunami político, social y judicial. Algunas de las personalidades más destacadas que se encuentran en el ojo del huracán son tan relevantes como: Ollanta Humala (ex presidente), Alejandro Toledo (ex presidente), Alan García (ex presidente), Pedro Pablo Kuckzynski (ex presidente), Keiko Fujimori (líder de la oposición), Nadine Heredia (ex primera dama), Félix Moreno (gobernador regional del Callao), Jorge Cuba (ex viceministro de Comunicaciones), etc. Redacción RPP Noticias. "Un año después, el caso Odebrecht sigue sacudiendo la política peruana”, RPP Noticias [en línea], 21 de diciembre del 2017, disponible en [http://rpp.pe/politica/judiciales/que-es-el-caso-odebrecht-y-como-afecta-alperu-noticia-1090099] (consulta: 27 de marzo de 2020).

73 Se ha podido probar que hubo complicidad de empresas con las dictaduras argentina, chilena y brasileña. 


\begin{tabular}{|c|c|c|}
\hline Seguridad & Contenido & Vinculación empresarial (ejemplos) \\
\hline $\begin{array}{l}\text { De la } \\
\text { comunidad }\end{array}$ & $\begin{array}{l}\text { Conflictividad social, } \\
\text { tensiones comunitarias, } \\
\text { religiosas o étnicas. }\end{array}$ & $\begin{array}{l}\text { Megaproyectos que afectan a comunidades } \\
\text { indígenas sin consentimiento libre, previo } \\
\text { e informado }{ }^{75} \text {. } \\
\text { Caso Renace }(\text { Guatemala) })^{76} \text {. }\end{array}$ \\
\hline
\end{tabular}

Los conceptos sobre fenómenos vinculados a la seguridad no constituyen compartimentos estancos sino que se diluyen, solapan e incluso convergen. No en vano, hoy está de moda el concepto de lo híbrido aplicado a las amenazas ${ }^{77}$, los conflictos

Además, corporaciones han participado en los conflictos armados de República Democrática del Congo, Sierra Leona y Angola, en la pugna por el comercio de diamantes. Juan Pablo Bohoslavsky y Marcelo Torelly. "Financial Complicity. The Brazilian Dictatorship under the "macroscope", en AA. VV. Justice and Economic Violence in Transition, Dustin N. Sharp (ed.), Nueva York, Springer, 2014, pp. 233 y ss.

74 En dicho caso, políticos y funcionarios de alto nivel en Brasil estaban implicados en una megacausa sobre corrupción que afectó la estabilidad democrática del país. Los implicados se encargaban de elaborar pliegos de condiciones a la medida, de gestionar las licitaciones y de garantizar la impunidad mediante sus contactos del más alto nivel. Regina Fonseca Fortes Furtado. "La colaboración premiada en la Ley Brasileña de Combate a las Organizaciones Criminales: su aplicación en el presunto caso de corrupción en la empresa Petrobrás", en AA. VV. Corrupción pública y privada en el Estado de derecho, Joan Queralt Jiménez y Dulce Santana Vega (dirs.), Valencia, Tirant lo Blanch, 2017, pp. 431-432.

75 Si un gobierno no hace públicos los estudios de impacto ambiental y la empresa interesada en cuestión tampoco facilita el acceso a la información a las comunidades locales afectadas, se estaría vulnerando el Derecho de acceso a la información. Además, esta situación reflejaría un doble problema: por un lado la deficiente actuación de la administración pública no revelando el estudio (quizás por corrupción) y, por otro, la falta de ética y honestidad de la empresa que se materializa en no ofrecer información para que el consentimiento requerido sea informado. Estos dos riesgos previsiblemente se verían aminorados si las dos organizaciones (Administración y empresa) hubieran tenido compliance. Real Academia de Ciencias Económicas y Financieras. Empresas a favor de las personas..., cit., p. 21.

76 La comunidad indígena quekchí, compuesta por más de 29.000 integrantes, padece una restricción muy fuerte de agua, como resultado de un proyecto hidroeléctrico que está llevando por subcontratación el Grupo Cobra (parte del conglomerado ACS) a lo largo del río Cahabón y que ha supuesto destrucción del curso del río, sin consulta ni consentimiento expreso de los pueblos indígenas. Así mismo, tales acciones han elevado la conflictividad social en la zona. Sobre los hechos controvertidos en cuestión, tal y como señala Greenpeace, "las graves carencias del procedimiento de evaluación ambiental y los fallos en el proceso de consulta a los pueblos indígenas [...] han producido un daño ambiental significativo". Nanqui Soto. "Acción/Cortamos el agua en las oficinas de Florentino mientras sigue restringiendo agua a los indígenas de Guatemala”, GreenPeace Noticias [en línea], 13 de abril de 2018, disponible en [https://es.greenpeace.org/es/noticias/actividadacs/] (consulta: 27 de marzo de 2020).

77 El contenido de dicho concepto se centra en subrayar "la mezcla de actividades coercitivas y subversivas, de métodos convencionales y no convencionales (es decir, diplomáticos, militares, económicos y tecnológicos), que pueden ser utilizados de forma coordinada por agentes estatales o no estatales para lograr objetivos específicos, manteniéndose por debajo del umbral de una guerra declarada. [...] la lucha contra las amenazas híbridas constituye un asunto de defensa y seguridad nacional y 
e incluso a la guerra. Por lo tanto, la academia debe reflexionar en cómo desde la actuación de las empresas se puede vulnerar la seguridad nacional de un determinado Estado. En el pasado solo los Estados u otro tipo de organizaciones criminales (crimen organizado y terrorismo) tenían dicha capacidad.

Por ejemplo, las empresas tecnológicas son muy importantes para amparar la seguridad humana y, especialmente, la seguridad nacional. No debemos olvidar que estos dos tipos de seguridad se complementan. La consideración de la seguridad humana permite a los Estados y a las personas una mejor recepción de los procesos de globalización ${ }^{78}$. Dentro de la globalización, el uso de la tecnología (inteligencia artificial ${ }^{79}$, robótica, big data, internet de las cosas, blockchain, criptomonedas, vehículos no tripulados, etc.) es uno de los elementos más esenciales a tener presente en términos de ciberseguridad y democracia ${ }^{80}$. La protección de los datos es fundamental para las personas, las administraciones y los Estados. Por ello, el compliance digital es una cuestión elemental que debe ser potenciada en el sector público y privado para la gestión y protección eficiente de la infraestructura crítica del país. Además, hay que advertir que "la nueva ciberseguridad se extiende más allá del campo meramente de la protección del patrimonio tecnológico para adentrarse en las esferas política ${ }^{81}$, económica ${ }^{82}$ y social"83.

Recientemente, Donald Trump ha señalado que en el espacio "se combaten guerras, igual que en la tierra, el aire y el mar"84. En la misma línea, Francia ha señalado que quiere satélites con armas tradicionales o láseres para el año 2030 como parte de su

de mantenimiento del orden público" (énfasis propio). Comisión Europea. Comunicación conjunta al Parlamento Europeo y al Consejo. Comunicación conjunta sobre la lucha contra las amenazas híbridas. Una respuesta de la Unión Europea. JOIN (2016) 18 final. Bruselas, 6 de abril de 2016, p. 2, disponible en [https://eur-lex.europa.eu/legal-content/ES/TXT/PDF/?uri=CELEX:52016JC0018\&from= ES] (consulta: 27 de marzo de 2020).

78 Francisco Rojas Aravena y Andrea Álvarez Marín. "Seguridad Humana. Un estado del arte", cit., p. 16.

79 Por ejemplo, en total la Unión Europea invertirá 20.000 millones $€$ al año en IA. Una empresa como Google invertirá lo mismo ella sola.

80 El uso contrario a la ética de la tecnología puede afectar a los procesos electorales, recientemente el caso Cambridge Analytica ha sido ejemplo de ello.

81 Se ha podido acreditar que las plataformas de redes sociales promocionaban el acceso a sitios virtuales con noticias falsas (fake news). World Economic Forum. Informe de riesgos mundiales 2018..., cit., p. 22. Nina Holland y Benjamin Sourice. El lobby de Monsanto..., cit., p. 48.

82 Por ejemplo, el uso de la tecnología para realizar espionaje corporativo y conseguir secretos de empresa.

83 Gobierno de España. Departamento de Seguridad Nacional. Estrategia Nacional de Ciberseguridad 2019, cit., p. 14.

84 Beatriz Juez. "Francia: 'El espacio es un nuevo frente a defender y debemos estar preparados"', en El Mundo [en línea], 25 de julio de 2019, disponible en [www.elmundo.es/internacional/2019/07/2 5/5d39c31421efa0f8508b46c9.html] (consulta: 25 de julio de 2019). 
estrategia de seguridad espacial. El objetivo es "poder defenderse no solo de eventuales países enemigos sino también de empresas privadas" 85 . El año pasado Francia acusó de espionaje a un satélite de propiedad rusa. En efecto, tecnología y empresa pueden ser utilizadas para promover la seguridad, pero también, este binomio es susceptible de generar inseguridad de forma directa o indirecta (retroalimentando otras amenazas). Las empresas solo responden a sus intereses, coincidiendo con lo que expresó Salvador Allende: “[L]a única patria de las empresas transnacionales es la ganancia" 86 . Lamentablemente, muchas empresas no están libres de corromperse afectando a la seguridad nacional o humana por la consecución de pingües beneficios.

Si las empresas no se centran únicamente en la búsqueda de dividendos, pueden convertirse en actores que aporten seguridad. La seguridad, en sentido amplio, exige contar con el sector privado para su consecución, y ello solo es posible sobre la base de entornos organizativos diligentes. El entendimiento privado y público debe producirse en un contexto de legalidad y ética. Es así que el compliance se convierte en una herramienta imprescindible en la interrelación de fenómenos y sujetos.

La corrupción como especie dentro de la delincuencia empresarial puede ser considerada el fenómeno más representativo en el ámbito socioeconómico por su impacto difuso y pluriofensivo. Ortés Caselles y Jiménez González han afirmado que la corrupción "genera una pérdida de legitimidad de las instituciones políticas y económicas" 87 . La corrupción desata una serie de consecuencias que tienen en común el debilitamiento del Estado de derecho y de las condiciones básicas para la convivencia pacífica. La corrupción provoca desconfianza, desafección, indignación y crispación ${ }^{88}$. Ello termina representándose en el incremento de la conflictividad y la exclusión social ${ }^{89}$. Complementariamente, hay que señalar que la corrupción

85 Carmen Menéndez. "Francia se prepara para la guerra espacial”, Euronews [en línea], 26 de julio de 2019, disponible en [https://es.euronews.com/2019/07/26/francia-se-prepara-para-la-guerra-espacial] (consulta: 26 de julio de 2019).

86 Gonzalo Fernández Ortiz de Zárate. Alternativas al poder corporativo..., cit., p. 12.

87 Joaquín Ortés Caselles y Juan Luis Jiménez González. “Efectos políticos y económicos de los escándalos de corrupción y de su difusión pública”, en AA. VV. Corrupción y desarrollo, Nicolás Rodríguez García y Fernando Rodríguez López (dirs.), Valencia, Tirant lo Blanch, 2017, p. 51.

88 Por eso, hay Estados que se toman en serio la lucha contra la corrupción y legislan al respecto. Sirva de ejemplo positivo en Francia, la Loi n. ${ }^{\circ}$ 2016-1691, relative à la transparence, à la lutte contre la corruption et à la modernisation de la vie économique, du 2016, conocida como Ley Sapin II. Desde esta ley, se obliga a las empresas o conglomerados empresariales con sede en Francia que cuenten con más de 500 empleados y facturación superior a 100 millones de euros a implementar un plan de cumplimiento anticorrupción. Además, la ley se aplicará a las empresas extranjeras ubicadas en Francia y a las empresas francesas radicadas en el exterior. Bernardo Del Rosal Blasco. Manual de responsabilidad penal y defensa penal corporativas. Madrid, Wolters Kluwer, 2018, pp. 196-197.

89 Ángel Bruno. “Apuntes sobre la corrupción y la Convención Interamericana”, en AA. VV. Compliance, anticorrupción y responsabilidad penal empresaria, Nicolás Durrieu y Raúl R. Saccani (dirs.), Buenos Aires, La Ley, 2018, p. 362. 
retroalimenta fenómenos que amenazan a la seguridad nacional ${ }^{90}$ como, por ejemplo, el crimen organizado. Desde la corrupción se alimenta la inseguridad y la vulneración de derechos humanos, ralentizándose, además, el desarrollo económico del país. Por estas razones, debemos defender la promoción de una cultura anticorrupción en lo público y lo privado a través del seguimiento de los estándares recogidos en la norma certificable Iso 37.001 Antisoborno.

Colombia no está exenta de los peligros enunciados. En un reciente caso ha podido documentarse cómo la corrupción pública interacciona con otras amenazas vinculadas al crimen organizado, el terrorismo y la actividad empresarial. Este es el caso de la Registraduría, en la que se vendían cedulas de nacionalidad y pasaportes a criminales nacionales y extranjeros. Como ha señalado el diario El Tiempo, "No se trata de hechos aislados. La Registraduría tiene evidencia de que un puñado de sus funcionarios está involucrado en una red de venta de documentos de ciudadanía colombianas a batallones de extranjeros bajo sospecha y a delincuentes locales vinculados a bandas y guerrilla. Entre la clientela también hay decenas de venezolanos que incluso podrían votar en las próximas elecciones y varios extranjeros, entre ellos potenciales terroristas" $"$. Este tipo de sucesos nos pone en alerta de cómo la corrupción pública es un auténtico desafío para la seguridad nacional y para el desarrollo de una democracia de calidad.Además, las conductas criminales en cuestión fueron posibles gracias a la "complicidad de ganaderías locales y de empresas de textiles"92.

Desde la perspectiva del Estado de derecho, hay que tener presente que ya hay quien ha calificado a las democracias actuales como corporatocracias ${ }^{93}$ o democracias

90 Por ejemplo, el Gobierno de Rusia en su Estrategia de Seguridad Nacional de 2015 identifica a la corrupción como una amenaza para la seguridad pública y estatal. Igualmente, el Libro Blanco de la Defensa Nacional de Perú señala que la corrupción está dentro de las amenazas internas a la seguridad y defensa nacional. En consonancia, la Política de Seguridad y Defensa Nacional de Perú de 2017 recoge la corrupción, los conflictos sociales y la contaminación ambiental como amenazas a la Seguridad del país. También la Estrategia de Seguridad Nacional de España de 2017 recoge la corrupción como factor de desestabilización. Russian Federation. Russian National Security Strategy, December 2015, pp. 9-14, disponible en [http://www.ieee.es/Galerias/fichero/OtrasPublicaciones/ Internacional/2016/Russian-National-Security-Strategy-31Dec2015.pdf] (consulta: 20 de mayo de 2020); Ministerio de Defensa de Perú. "Capítulo III: Política de Estado para la Seguridad y la Defensa Nacional”, en Libro Blanco de la Defensa Nacional, Lima, abril de 2005, p. 63, disponible en [https://www.mindef.gob.pe/informacion/documentos/libroblanco/Capitulo_III.pdf] (consulta: 6 de mayo de 2020); Decreto Supremo n. ${ }^{\circ}$ 012-2017-DE (Perú), que aprueba la Política de Seguridad y Defensa Nacional, de 22 de diciembre de 2017; y Gobierno de España. Presidencia del Gobierno. Estrategia de Seguridad Nacional 2017. Un proyecto compartido de todos y para todos. [Madrid], Boletín Oficial del Estado, 2017, pp. 70-71, disponible en [https://www.dsn.gob.es/sites/dsn/files/ Estrategia_de_Seguridad_Nacional_ESN\%20Final.pdf] (consulta: 7 de marzo de 2020).

91 Unidad Investigativa. "Así opera la poderosa mafia transnacional que ronda a la Registraduría”, El Tiempo [en línea], 26 de enero de 2020, disponible en [www.eltiempo.com/unidad-investigativa/asiopera-la-mafia-transnacional-que-ronda-a-la-registraduria-404530] (consulta: 20 de marzo de 2020).

92 Ídem.

93 Susan George. Los usurpadores..., cit., p. 18. 
devaluadas ${ }^{94}$, como consecuencia del poder de los lobbies empresariales y de los numerosos casos de corrupción en los partidos políticos ${ }^{95}$. Debemos insistir en la necesidad de regeneración de las instituciones. Ello es posible desde el compliance, pues permite reforzar la cultura de legalidad y ética de los partidos políticos. En consecuencia, es necesario realizar esfuerzos orientados a la mejora de los mecanismos de gobernanza (su democracia interna ${ }^{96}$ ) y de sus sistemas de control (internos y externos). Del lado público, el fomento de los marcos de integridad y las medidas de public compliance serán nuestros mejores aliados, junto con la transparencia material, la rendición de cuentas y el Gobierno Abierto.

En España, la Ley Orgánica 3/2015, del 30 de marzo, de control de la actividad económico financiera de los partidos políticos en su artículo 9 bis señala que los partidos políticos, deberán incorporar "un sistema de prevención de conductas contrarias al ordenamiento jurídico". En definitiva, el modelo de compliance recogido en el artículo 31 bis CP será un modelo apropiado para mejorar de forma directa el funcionamiento de los partidos políticos y de forma indirecta elevar la calidad de nuestra democracia e instituciones.

Los programas de cumplimiento normativo en la vida política colombiana también serían muy recomendables. No ha sido infrecuente relacionar a los partidos políticos con la corrupción. Según datos recientes ofrecidos por la Corporación Transparencia por Colombia, "de los 1101 alcaldes, 12.061 concejales y 32 gobernadores electos para el periodo 2016-2019 el 52,4\% estuvo investigado, sancionado o inhabilitado por hechos de corrupción" 97 . Algunos de estos casos han sido dramáticos, como el sucedido en el municipio de Albania, donde la corrupción usurpaba los fondos de programas orientados a reducir la mortalidad infantil. Igualmente, la financiación irregular de los partidos políticos (directamente o desde sus fundaciones), la compra de votos, la participación de grupos armados ilegales en jornadas electorales, las irregularidades en los avales a candidatos y la obstrucción de procesos de revocatoria de mandado son conductas que también acontecen ${ }^{98}$. En los casos más graves se producen asesinatos de candidatos y líderes políticos ${ }^{99}$.

94 Gonzalo Fernández Ortiz de Zárate. Alternativas al poder corporativo..., cit., pp. 50-51.

95 En los últimos años se han imputado hasta 1900 políticos y condenado a cerca de 200. Antonio López Álvarez. "Los partidos políticos en España: constitucionalización, régimen legal, democracia interna y corrupción”, en AA. VV. La corrupción política en España: una visión ética y jurídica, Antonio López Álvarez y Juan José García Navarro (coords.), Navarra, Aranzadi, 2016, p. 44.

96 Art. 6 CE. "[...] Su estructura interna y funcionamiento deberán ser democráticos".

97 Corporación Transparencia por Colombia. Así se mueve la corrupción. Radiografía de los hechos de corrupción en Colombia 2016-2018, Monitor Ciudadano tercer informe, Bogotá, mayo 2019, p. 52 , disponible en [https://transparenciacolombia.org.co/Documentos/2019/Informe-Monitor-CiudadanoCorrupcion-18.pdf] (consulta: 20 de mayo de 2020).

98 Ibídem, pp. 46 y ss.

99 María Alejandra Navarrete. “¿Por qué asesinan a candidatos y líderes políticos en Colombia?”, en 


\subsection{La responsabilidad social corporativa y los Objetivos de Desarrollo Sostenible desde el cumplimiento normativo y la delincuencia empresarial}

Una versión sencilla del concepto de responsabilidad social corporativa (RSC) podemos obtenerla del Libro Verde de la Comisión de las Comunidades Europeas. En él se señala que la RSC es el concepto según el cual "las empresas deciden voluntariamente contribuir al logro de una sociedad mejor y un medio ambiente más limpio" ${ }^{100}$. Un concepto más extenso nos permite conocer el fenómeno de forma más integral. En ese sentido, Cajiga afirma que la RSC es

una forma de gestión y de hacer negocios, en la cual la empresa se ocupa de que sus operaciones sean sustentables en lo económico, lo social y lo ambiental, reconociendo los intereses de los distintos grupos con los que se relaciona y buscando la preservación del medio ambiente y la sustentabilidad de las generaciones futuras. Es una visión de negocios que integra el respeto por las personas, los valores éticos, la comunidad y el medioambiente con la gestión misma de la empresa, independientemente de los productos o servicios que ésta ofrece, del sector al que pertenece, de su tamaño o nacionalidad ${ }^{101}$.

Hay que señalar que la incorporación en la empresa de acciones de RSC tiene grandes ventajas, entre ellas: menor absentismo laboral, incremento de la motivación de los trabajadores, mejora del clima laboral ${ }^{102}$, incentiva el contacto con la sociedad de forma positiva, mejorando, además, su legitimidad social, incrementa el valor de la imagen de la empresa, reduce costes y riesgos, otorga ventajas competitivas, etc. ${ }^{103}$. Pero las ventajas no son solo para la empresa. La ciudadanía también valora positivamente que la empresa reduzca las externalidades negativas propias de su actividad

Insight Crime. Investigación y análisis del Crimen Organizado [en línea], 12 de septiembre de 2019, disponible en [https://es.insightcrime.org/noticias/analisis/asesinan-candidatos-colombia/] (consulta: 27 de marzo de 2020).

100 Comisión de las Comunidades Europeas. Libro Verde. Fomentar un marco europeo para la responsabilidad social de las empresas. COM (2001) 366 final. Bruselas, 17 de julio de 2001, p. 4, disponible en [http://www.europarl.europa.eu/meetdocs/committees/deve/20020122/com(2001)366_es.pdf] (consulta: 27 de marzo de 2020).

101 Juan Felipe Cajiga Calderón. El concepto de responsabilidad social empresarial [México], Centro Mexicano para la Filantropía, 2010,p. 2, disponible en [https://www.cemefi.org/esr/images/stories/ pdf/esr/concepto_esr.pdf] (consulta: 27 de marzo de 2020).

102 El compliance laboral es positivo para el empleador (minimiza riesgos laborales) pero también para el empleado (existe un mayor respeto por sus derechos). Se recomienda: Raúl Rojas Rosco; Erika Moraleja Moraleja y Roberto Gutiérrez Arranz. Compliance Laboral. Madrid, 2017, passim.

103 Nuria de Querol e Inés Gomis. "Gestión de valores y responsabilidad social”, en AA. VV. La gestión de valores en la empresa como aportación de valor. Anna Bajo Sanjuan y Nuria Villagra García (eds.), Madrid, Universidad Pontificia Comillas, 2015, p. 84; Juan Felipe Cajiga Calderón. El concepto de responsabilidad social empresarial..., cit., p. 17. 
económica y, a la vez, mejore su transparencia y ética corporativa. El problema es que la RSC no comporta sanciones para la empresa frente al incumplimiento de las exigencias que se autoimpone, por lo tanto, pueden llegar a considerarse simplemente como declaraciones de buena voluntad. Desde esta perspectiva es muy difícil lograr que las empresas se impliquen en la consecución de los Objetivos de Desarrollo Sostenible pese a ser tareas muy importantes que en su mayoría se vinculan a la protección de los derechos humanos como a continuación veremos.

Se expone en el cuadro n. ${ }^{\circ} 2$ la relación que existe entre los Objetivos de Desarrollo Sostenible ${ }^{104}$ y sus metas, asignándose determinados ejemplos de cumplimiento o delincuencia empresarial para cada bloque.

\section{Cuadro n. ${ }^{\circ}$ 2. Objetivos de Desarrollo Sostenible, metas y casos en el mundo que requieren del cumplimiento de estos}

\begin{tabular}{|c|l|}
\hline ODS 1 & Poner fin a la pobreza en todas sus formas en todo el mundo. \\
\hline Meta & $\begin{array}{l}\text { "De aquí a } 2030 \text {, fomentar la resiliencia de los pobres y las personas que } \\
\text { se encuentran en situaciones de vulnerabilidad y reducir su exposición y } \\
\text { vulnerabilidad a los fenómenos extremos relacionados con el clima y otras } \\
\text { perturbaciones y desastres económicos, sociales y ambientales." }\end{array}$ \\
\hline Ejemplo & Depredación en los mares provocada por los buques pesqueros chinos ${ }^{105}$. \\
\hline
\end{tabular}

\begin{tabular}{|c|l|}
\hline ODs 2 & $\begin{array}{l}\text { Poner fin al hambre, lograr la seguridad alimentaria y la mejora de la nutri- } \\
\text { ción y promover la agricultura sostenible. }\end{array}$ \\
\hline Meta & $\begin{array}{l}\text { "Adoptar medidas para asegurar el buen funcionamiento de los mercados de } \\
\text { productos básicos alimentarios y sus derivados y facilitar el acceso oportuno } \\
\text { a la información sobre los mercados, incluso sobre las reservas de alimentos, a } \\
\text { fin de ayudar a limitar la extrema volatilidad de los precios de los alimentos." }\end{array}$ \\
\hline Ejemplo & Industria del aguacate y la palta en Chile106. \\
\hline
\end{tabular}

(continúa)

104 Cepal-Naciones Unidas. Agenda 2030 y los Objetivos de Desarrollo Sostenible. Una oportunidad para América Latina y el Caribe [en línea] (LC/G.2681-P/Rev.3), Santiago, diciembre 2018, passim, disponible en [https://repositorio.cepal.org/bitstream/handle/11362/40155/24/S1801141_es.pdf] (consulta: 27 de marzo de 2020).

105 "El buque chino Fu Yuan Yu Leng 999 fue capturado en agosto del 2017 en la Reserva Marina de Galápagos con 300 toneladas de pesca y al menos dos especies de tiburón consideradas vulnerables." Redacción Diario ElComercio.com. "Ecuador despliega buques y aviones militares por flota de pesca china en Galápagos", El Comercio, 25 de abril de 2019, disponible en [www.elcomercio. com/actualidad/flota-china-aviones-ffaa-galapagos.html] (consulta: 27 de marzo de 2020).

106 La industria del aguacate y la palta, que necesitan ingentes cantidades de agua para su producción, ha dejado sin agua disponible a las comunidades locales. Cada hectárea de palta demanda 100.000 litros de agua diarios. "Petorca, el símbolo de la guerra por el agua en Chile", France 24 [en línea], 


\begin{tabular}{|c|l|}
\hline ODS 3 & $\begin{array}{l}\text { Garantizar una vida sana y promover el bienestar para todos en todas las } \\
\text { edades. }\end{array}$ \\
\hline Meta & $\begin{array}{l}\text { "De aquí a 2030, reducir considerablemente el número de muertes y enfer- } \\
\text { medades causadas por productos químicos peligrosos y por la polución y } \\
\text { contaminación del aire, el agua y el suelo." }\end{array}$ \\
\hline Ejemplo & Industria agropecuaria contamina suelos y aguas de forma desmedida ${ }^{107}$. \\
\hline
\end{tabular}

\begin{tabular}{|c|l|}
\hline ODS 4 & $\begin{array}{l}\text { Garantizar una educación inclusiva, equitativa y de calidad y promover } \\
\text { oportunidades de aprendizaje durante toda la vida para todos. }\end{array}$ \\
\hline Meta & $\begin{array}{l}\text { "Construir y adecuar instalaciones educativas que tengan en cuenta las } \\
\text { necesidades de los niños y las personas con discapacidad y las diferencias } \\
\text { de género, y que ofrezcan entornos de aprendizaje seguros, no violentos, } \\
\text { inclusivos y eficaces para todos." }\end{array}$ \\
\hline Ejemplo & $\begin{array}{l}\text { Universidades éticas e igualitarias con sólidos programas de cumplimiento } \\
\text { que incluyan protocolos frente al acoso sexual }{ }^{108} \text { y al acoso sexista. }\end{array}$ \\
\hline
\end{tabular}

\begin{tabular}{|c|l|}
\hline ODS 5 & $\begin{array}{l}\text { Lograr la igualdad entre los géneros y empoderar a todas las mujeres y las } \\
\text { niñas. }\end{array}$ \\
\hline Meta & $\begin{array}{l}\text { "Eliminar todas las formas de violencia contra todas las mujeres y las niñas } \\
\text { en los ámbitos público y privado, incluidas la trata y la explotación sexual } \\
\text { y otros tipos de explotación." }\end{array}$ \\
\hline Ejemplo & Prevención de la trata en hoteles, clubes y agencias de modelos ${ }^{109}$. \\
\hline
\end{tabular}

(continúa)

22 de marzo de 2018, disponible en [https://www.france24.com/es/20180322-petorca-el-simbolode-la-guerra-por-el-agua-en-chile] (consulta: 27 de marzo de 2020).

107 El abuso de fertilizantes provoca contaminación de nitrógeno y potasio que acelera la acidificación de los océanos, a lo que se suma la emisión de gases de efecto invernadero. Ambos fenómenos contribuyen al calentamiento global. María del Mar Hidalgo García. "La influencia de los servicios de los ecosistemas en la seguridad: el caso de la pesca”, Documento de Análisis del Instituto Español de Estudios Estratégicos [en línea], n. ${ }^{\circ}$ 24, 27 de junio de 2018, p. 3, disponible en [http://www. ieee.es/Galerias/fichero/docs_analisis/2018/DIEEEA24-2018_Servicios_Ecosistemas_Pesca_MMHG. pdf] (consulta: 27 de marzo de 2020).

108 El juzgado de lo penal número 2 de Sevilla ha condenado a siete años de prisión al exdecano de la Facultad de Ciencias de la Educación por haber abusado sexualmente de dos profesoras ayudantes de su departamento y una becaria de investigación entre los años 2006 y 2010. El juez considera al autor responsable de tres delitos continuados de abusos sexuales y otro de lesiones psicológicas. El catedrático había amenazado a las mujeres con hacerles perder sus puestos, impidiéndoles leer sus tesis o apuntarse a los grupos de investigación o les exigía aparecer como coautor de las publicaciones que éstas hacían.

109 Como ha señalado Ontiveros, "hay empresas vinculadas a la trata de personas, a la explotación de prostitución ajena incluida la infancia”. Miguel Ontiveros. "Casinos, compliance y sistema penal. 


\begin{tabular}{|c|l|}
\hline ODS 6 & $\begin{array}{l}\text { Garantizar la disponibilidad de agua y su gestión sostenible y el saneamiento } \\
\text { para todos. }\end{array}$ \\
\hline Meta & $\begin{array}{l}\text { "De aquí a 2020, proteger y restablecer los ecosistemas relacionados con } \\
\text { el agua, incluidos los bosques, las montañas, los humedales, los ríos, los } \\
\text { acuíferos y los lagos." }\end{array}$ \\
\hline Ejemplo & $\begin{array}{l}\text { Chevron, contaminación de las únicas fuentes de agua potable de comu- } \\
\text { nidades locales }{ }^{110}\end{array}$ \\
\hline
\end{tabular}

\begin{tabular}{|c|l|}
\hline ODS 7 & $\begin{array}{l}\text { Garantizar el acceso a una energía asequible, segura, sostenible y moderna } \\
\text { para todos. }\end{array}$ \\
\hline Meta & $\begin{array}{l}\text { "De aquí a 2030, duplicar la tasa mundial de mejora de la eficiencia ener- } \\
\text { gética." }\end{array}$ \\
\hline Ejemplo & $\begin{array}{l}\text { El precio de la electricidad se encarece como consecuencia de fraudes de } \\
\text { fluido eléctrico realizados por empresas }\end{array}$ \\
\hline
\end{tabular}

\begin{tabular}{|c|l|}
\hline ODS 8 & $\begin{array}{l}\text { Promover el crecimiento económico sostenido, inclusivo y sostenible, el } \\
\text { empleo pleno y productivo y el trabajo decente para todos. }\end{array}$ \\
\hline Meta & $\begin{array}{l}\text { "Proteger los derechos laborales y promover un entorno de trabajo seguro y } \\
\text { sin riesgos para todos los trabajadores, incluidos los trabajadores migrantes, } \\
\text { en particular las mujeres migrantes y las personas con empleos precarios." }\end{array}$ \\
\hline Ejemplo & $\begin{array}{l}\text { Implementación de cláusulas contractuales que faciliten controles de forma } \\
\text { directa e ilimitada sobre los proveedores, especialmente en el sector textill12. }\end{array}$ \\
\hline
\end{tabular}

(continúa)

Fundamentos del juego responsable", en Anuario Mexicano de Derecho Penal Económico, n. ${ }^{\circ}$, 2015, p. 296.

110 Cuando Texaco, hoy Chevron, abandonó Ecuador dejó atrás vertidos tóxicos en ríos por una cantidad de más de 18.500 millones de galones, además de, 900 pozos de residuos abiertos que había acumulado durante un largo periodo de 25 años. Estos vertidos dañaron gravemente el medio ambiente, ya que se filtraban hacia las únicas fuentes de agua que las comunidades locales disponían. Chris Jochnick. "¿Qué implicaciones tiene la sentencia contra Chevron por \$18 mil millones de dólares?", Aportes DPLF: Revista para la Fundación del Debido Proceso, 15, septiembre de 2011, p. 46, disponible en [http://www.dplf.org/sites/default/files/1317248743_1.pdf] (consulta: 20 de mayo de 2020).

111 Endesa. "El 96\% del fraude eléctrico se debe a empresas y a particulares con un elevado nivel de consumo". Endesa. Sala de Prensa [en línea], 4 de agosto de 2015, disponible en [https://www. endesa.com/es/prensa/news/d201608-el-96-del-fraude-elctrico-se-debe-a-empresas-y-a-particularescon-un-elevado-nivel-de-consumo.html] (consulta: 20 de marzo de 2020).

112 En el sur de la India los niños trabajan en el sector textil en condiciones estremecedoras, elaborando prendas que serán distribuidas por las multinacionales en el primer mundo. José María Ayala de la Torre. Claves Prácticas. Compliance. Madrid, Francis Lefebvre, 2016, p. 136. 


\begin{tabular}{|c|l|}
\hline ODS 9 & $\begin{array}{l}\text { Construir infraestructuras resilientes, promover la industrialización inclusiva } \\
\text { y sostenible y fomentar la innovación. }\end{array}$ \\
\hline Meta & $\begin{array}{l}\text { "Aumentar el acceso de las pequeñas industrias y otras empresas, particu- } \\
\text { larmente en los países en desarrollo, a los servicios financieros, incluidos } \\
\text { créditos asequibles, y su integración en las cadenas de valor y los mercados." }\end{array}$ \\
\hline Ejemplo & Implementación de programas de cumplimiento en las pymes ${ }^{113}$. \\
\hline
\end{tabular}

\begin{tabular}{|c|l|}
\hline ODS 10 & Reducir la desigualdad en y entre los países. \\
\hline Meta & $\begin{array}{l}\text { "Adoptar políticas, especialmente fiscales, salariales y de protección social, } \\
\text { y lograr progresivamente una mayor igualdad." }\end{array}$ \\
\hline Ejemplo & $\begin{array}{l}\text { Implementar en los procesos de licitaciones públicas cláusulas de con- } \\
\text { tratación pública socialmente responsable que penalicen la participación } \\
\text { empresarial en paraísos fiscales }\end{array}$ \\
\hline
\end{tabular}

\begin{tabular}{|c|l|}
\hline ODS 11 & $\begin{array}{l}\text { Lograr que las ciudades y los asentamientos humanos sean inclusivos, se- } \\
\text { guros, resilientes y sostenibles. }\end{array}$ \\
\hline Meta & $\begin{array}{l}\text { "De aquí a 2030, reducir el impacto ambiental negativo per cápita de las } \\
\text { ciudades, incluso prestando especial atención a la calidad del aire y la ges- } \\
\text { tión de los desechos municipales y de otro tipo." }\end{array}$ \\
\hline Ejemplo & $\begin{array}{l}\text { Implementación de mecanismos de control a basureros municipales públicos } \\
\text { y privados. Caso "Önerylidiz vs. Turquía"115. }\end{array}$ \\
\hline
\end{tabular}

(continúa)

113 "Las empresas que mejor puedan acreditar la existencia y la eficacia de un modelo de cumplimiento tendrán una ventaja superior en los concursos convocados por entidades públicas y por empresas privadas para la contratación de productos o servicios." Xavier Ribas. "25 argumentos a favor del Compliance", en AA. vV. Practicum Compliance, Xavier Ribas (dir.), Pamplona, Aranzadi, 2018, p. 46; Ilias Bantekas. "Corruption as an International Crime and Crime against Humanity: An Outline of Supplementary Criminal Justice Policies", Journal of International Criminal Justice, vol. 4, n. ${ }^{\circ}$ 3, 2006, p. 481.

114 Gonzalo Fernández Ortiz de Zárate. Alternativas al poder corporativo..., cit., p. 148.

115 El Tribunal Europeo de Derechos Humanos tuvo que pronunciarse sobre un asunto relacionado con la seguridad humana, al tratarse de un caso de degradación ambiental con fuertes componentes de pobreza urbana. En concreto, murieron fruto de una explosión 39 personas que vivían en un asentamiento irregular, frente a un basurero de titularidad pública. En el caso se observó que el basurero municipal disponía de información en la que se expresaba que había una situación de riesgo de explosión para la vida de los habitantes pobres que allí vivían, resultado de los descuidos y de la actividad propia del basurero municipal. TEDH, sentencia n. ${ }^{\circ}$ 48939/99, 30 de noviembre de 2004, parágrafo número 100 . 


\begin{tabular}{|c|l|}
\hline ODS 12 & Garantizar modalidades de consumo y producción sostenibles. \\
\hline Meta & $\begin{array}{l}\text { "Alentar a las empresas, en especial las grandes empresas y las empresas } \\
\text { transnacionales, a que adopten prácticas sostenibles e incorporen informa- } \\
\text { ción sobre la sostenibilidad en su ciclo de presentación de informes." }\end{array}$ \\
\hline Ejemplo & Apple y Samsung: obsolescencia programada ${ }^{116}$. \\
\hline
\end{tabular}

\begin{tabular}{|c|l|}
\hline ODS 13 & Adoptar medidas urgentes para combatir el cambio climático y sus efectos. \\
\hline Meta & $\begin{array}{l}\text { "Fortalecer la resiliencia y la capacidad de adaptación a los riesgos relacio- } \\
\text { nados con el clima y los desastres naturales en todos los países." }\end{array}$ \\
\hline Ejemplo & $\begin{array}{l}\text { Promover desde el sector público (normativa) y desde el sector privado } \\
\text { (RSC) el reciclaje y las soluciones de gestión empresarial orientadas hacia } \\
\text { la eco-eficiencia }{ }^{117} \text {. }\end{array}$ \\
\hline
\end{tabular}

\begin{tabular}{|c|l|}
\hline ODS 14 & $\begin{array}{l}\text { Conservar y utilizar en forma sostenible los océanos, los mares y los recursos } \\
\text { marinos para el desarrollo sostenible. }\end{array}$ \\
\hline Meta & $\begin{array}{l}\text { "De aquí a 2020, gestionar y proteger sosteniblemente los ecosistemas mari- } \\
\text { nos y costeros para evitar efectos adversos importantes, incluso fortaleciendo } \\
\text { su resiliencia, y adoptar medidas para restaurarlos a fin de restablecer la } \\
\text { salud y la productividad de los océanos." }\end{array}$ \\
\hline Ejemplo & $\begin{array}{l}\text { Promocionar el compliance en el sector de la pesca para dotarlo de trans- } \\
\text { parencia e incrementar los mecanismos de represión de la delincuencia } \\
\text { pesquera (arts. 334 y 335 CP y art. 2.2 L. O. 12/1995, del 12 de diciembre, } \\
\text { de represión del contrabando) }\end{array}$ \\
\hline
\end{tabular}

(continúa)

116 Dichas compañías han sido sancionadas en Italia por obsolescencia programada, en la que ha sido la primera sanción en el mundo en virtud de tal concepto, por constituir una práctica comercial injusta. Así, las autoridades italianas de competencia han impuesto sanciones económicas de diez millones de euros a Apple y de cinco millones de euros a Samsung por violar los artículos 20, 21, 22 y 24 del Código de Consumidores. EFE. Agencia de Noticias. "Apple y Samsung, multadas en Italia por la obsolescencia programada", El Mundo [en línea], 25 de octubre de 2018, disponible en [https://www.elmundo.es/tecnologia/2018/10/24/5bd055e046163fa49c8b45aa.html] (consulta: 20 de marzo de 2020).

117 Ignacio Lledó Benito. Corporate compliance: la prevención de riesgos penales y delitos en las organizaciones penalmente responsables. Madrid, Dykinson, 2018, p. 104.

118 Es importante saber, tal como señala María del Mar Hidalgo García, "La influencia de los servicios de los ecosistemas...", cit., p. 8, que, "según la FAO, el 31\% de las reservas pesqueras están sobreexplotadas y el 58\% están explotadas completamente". Lo cierto es que si el tráfico de especies no afecta a especies protegidas por el convenio cITES tampoco entrará en aplicación la responsabilidad penal de la persona jurídica por la vía del contrabando (art. 3.6 Ley de represión del contrabando). Además, la persecución de la pesca ilegal se complica en aguas internacionales y de terceros países por cuestiones de competencia jurisdiccional como ocurrió con el famoso "clan Vidal" que fue absuelto por el Tribunal Supremo (sentencia 974/2016 del 23 de diciembre). Rafael Méndez. 


\begin{tabular}{|c|l|}
\hline ODS 15 & $\begin{array}{l}\text { Promover el uso sostenible de los ecosistemas terrestres, luchar contra la } \\
\text { desertificación, detener e invertir la degradación de las tierras y frenar la } \\
\text { pérdida de la diversidad biológica. }\end{array}$ \\
\hline Meta & $\begin{array}{l}\text { "Adoptar medidas urgentes y significativas para reducir la degradación de } \\
\text { los hábitats naturales, detener la pérdida de biodiversidad y, de aquí a 2020, } \\
\text { proteger las especies amenazadas y evitar su extinción." }\end{array}$ \\
\hline Ejemplo & Empresas madereras depredadoras ${ }^{119}$. \\
\hline
\end{tabular}

\begin{tabular}{|c|l|}
\hline ODS 16 & $\begin{array}{l}\text { Promover sociedades pacíficas e inclusivas para el desarrollo sostenible, } \\
\text { facilitar el acceso a la justicia para todos y crear instituciones eficaces, res- } \\
\text { ponsables e inclusivas a todos los niveles. }\end{array}$ \\
\hline Meta & "Reducir considerablemente la corrupción y el soborno en todas sus formas." \\
\hline Ejemplo & $\begin{array}{l}\text { Necesidad de implementación de programas de cumplimiento en empresas } \\
\text { semipúblicas para evitar situaciones como el caso Defex }\end{array}$ \\
\hline
\end{tabular}

\begin{tabular}{|c|l|}
\hline oDS 17 & $\begin{array}{l}\text { Fortalecer los medios de ejecución y revitalizar la Alianza Mundial para } \\
\text { el Desarrollo Sostenible. }\end{array}$ \\
\hline Meta & $\begin{array}{l}\text { "Aumentar la estabilidad macroeconómica mundial, incluso mediante la } \\
\text { coordinación y coherencia de las políticas." }\end{array}$ \\
\hline Ejemplo & $\begin{array}{l}\text { La estabilidad macroeconómica no es posible sin trasparencia en los mer- } \\
\text { cados o si se producen fraudes masivos. Considérese, por ejemplo, el caso } \\
\text { Bankia }^{121} \text {. }\end{array}$ \\
\hline
\end{tabular}

Fuente: elaboración propia.

"El Supremo deja impune la pesca 'pirata' en alta mar: así escapó el clan Vidal de la justicia”, $E l$ Confidencial, 10 de febrero de 2017, disponible en [www.elconfidencial.com/espana/2017-02-10/ supremo-deja-impune-pesca-pirata-alta-mar-asi-escapo-clan-vidal-justicia_1327354/] (consulta: 27 de marzo de 2020).

119 Como ha señalado el Grupo del poblado Obeng Obuc en Guinea Ecuatorial, "Nuestros bosques van fatal. Los bosques están destruidos por las empresas". Magbma y Fao. Estudio de las causas de la deforestación y degradación forestal en Guinea Ecuatorial (2004-2014), República de Guinea Ecuatorial, 2018, p. 25, disponible en [http://www.fao.org/3/CA0399ES/ca0399es.pdf] (consulta: 27 de marzo de 2020).

120 En tal caso, se produjo la venta irregular de material de seguridad y defensa al Gobierno de Angola. En la investigación están implicadas hasta 27 personas, en delitos que implican corrupción de funcionario público extranjero, blanqueo de capitales, falsedad documental, malversación de caudales públicos, apropiación indebida y delitos fiscales. "Anticorrupción pide al juez que procese a 27 personas por la presunta venta irregular de armas de Defex a Angola", EuropaPress [en línea], 18 de abril de 2018, disponible en [http://www.europapress.es/nacional/noticia-anticorrupcion-pidejuez-procese-27-personas-presunta-venta-irregular-armas-defex-angola-20180418122601.html] (consulta: 27 de marzo de 2020).

121 Produciéndose una estafa masiva a ahorradores, que sin saberlo ni tener el perfil de inversores profesionales suscribieron acciones que tenían un elevado riesgo. "El grupo BFA-Bankia recibió 
Si la RSC pretende tener cierto valor en la sociedad no puede ser una simple declaración de buenas intenciones sino que debe someterse a los mecanismos de monitoreo propios del programa de cumplimiento para verificar que aquello que se promete a la sociedad, realmente se está cumpliendo. De otro modo, (a) la empresa genera unas falsas expectativas en la sociedad; (b) evade su responsabilidad con el entorno; (c) no contribuye a la consecución de los derechos humanos y la seguridad humana y (d) resulta antiética e incoherente, pues habiéndose comprometido con unos objetivos no ejecuta acciones para su logro, o incluso, actúa en contra de tales objetivos.

Tomarse en serio la consecución de los Objetivos de Desarrollo Sostenible exige que estos sean asumidos en las empresas a través de sus mecanismos de autorregulación y que dichos compromisos sean monitoreados a través de sus sistemas de cumplimiento normativo, pues de otro modo no se lograrán avances, ya que serán esfuerzos puntuales y sesgados orientados únicamente a mejorar la imagen de la marca. Sirva de ejemplo que el último informe del SGD Index and Dashboards Report señala que España no ha logrado ninguno de los 17 ODS $^{122}$. Solo el $14 \%$ de las empresas cotizadas españolas informa de la existencia en sus empresas del mecanismo de gobernanza de la sostenibilidad ${ }^{123}$. Un raquítico $15 \%$ reporta los derechos humanos en su cadena de valor. Apenas un 33,3\% contempla políticas medioambientales ${ }^{124}$.

Por tanto, el logro de los ODS no puede seguir siendo una simple cuestión de RSC sin ningún tipo de presión o exigencia ${ }^{125}$. El compliance puede dotar de mayor eficacia, credibilidad y control a los esfuerzos que se realizan desde el ámbito empresarial para el logro de los oDs. Vincular los oDs con el programa de cumplimiento mejora el rendimiento de la empresa en la consecución de los oDs, la seguridad humana y la protección de los derechos humanos ya que el compliance es una cuestión de acción y no sólo de buenas intenciones.

En cumplimiento normativo se valoran y evalúan los hechos acreditables. Por ello, las acciones orientadas al control y supervisión de la empresa deben quedar integralmente

en diciembre del 2012 una inyección de capital por un importe de 18.000 millones de euros. Los accionistas que invirtieron en la salida a Bolsa han perdido en menos de dos años la mayoría de su inversión. José Gallizo y Xavier Sabi. "Bankia y la transparencia necesaria", Revista de Contabilidad y Dirección, vol. 1, n. ${ }^{\circ} 16,2013$, p. 263.

122 Observatorio de los Ods/Esade. La contribución de las empresas españolas a los objetivos de desarrollo sostenible. Segundo informe. Barcelona, mayo de 2019, p. 4, disponible en [https:// obrasociallacaixa.org/documents/10280/825331/la_contribucion_de_las_empresas_espanolas_a_ los_ods_segundo_informe_es.pdf] (consulta: 27 de marzo de 2020).

123 Ibídem, p. 8.

124 Ibídem, p. 39.

125 "Siendo realistas y teniendo en cuenta nuestras fuerzas y nuestros medios económicos, probablemente el Pacto Mundial continuará impulsando sus insensatas e inútiles 'soluciones', contribuyendo a prolongar la ficción de la responsabilidad social corporativa.” Susan George. Los usurpadores..., cit., p. 180. 
reflejadas (por escrito o en soporte electrónico) y custodiadas fielmente, a efectos de que pueda acreditarse en un momento posterior la efectiva veracidad, racionalidad y adecuación de las medidas llevadas a cabo. Una empresa ética, con buena gobernanza y compliance, se encuentra en una posición privilegiada para contribuir a la mejora de nuestras sociedades como parte de su compromiso con la sociedad.

Las multinacionales consiguen la justicia económica que les interesa a través de los tribunales internacionales de arbitraje que se estipulan en los tratados de libre comercio (TTIP, TTP o CETA). Sin embargo, la salvaguarda de los derechos humanos siempre queda relegada en la agenda internacional al no interesar a las multinacionales, especialmente a las del llamado "primer mundo". Ante dicho contexto, hay que afirmar que "necesitamos desesperadamente leyes impositivas que impidan a las corporaciones destruir la democracia, los derechos humanos y la vida misma"126. La lesividad de la delincuencia corporativa es ingente, por ello durante el discurso de final de campaña electoral de Roosevelt, celebrado en Nueva York allá en el año 1936 (tiempo después de la Gran Recesión), se afirmó lo siguiente sobre el poder de las grandes corporaciones financieras: "Sabemos ahora que un gobierno del dinero organizado es tan peligroso como un gobierno de la mafia organizada".

La multitud de conductas empresariales contra el medio ambiente y otros bienes jurídicos que han quedado impunes motiva la aparición de iniciativas orientadas a solicitar la creación de:

- un Tribunal Internacional Medioambiental;

- un Tribunal Internacional de la Justicia Climática ${ }^{127}$;

- un instrumento internacional jurídicamente vinculante sobre las empresas transnacionales y otras empresas con respecto a los derechos humanos ${ }^{128}$;

- una Corte Mundial sobre Corporaciones Trasnacionales y Derechos Humanos;

- un Centro Público para el Control de Empresas Trasnacionales;

- un Tratado Internacional de los Pueblos para el Control de las Empresas Transnacionales ${ }^{129}$.

126 Ibídem, p. 82.

127 Rosel Soler Fernández. "El ecocidio: ¿crimen internacional?”, Documento de Opinión del Instituto Español de Estudios Estratégicos [en línea], n. ${ }^{\circ} 128,21$ de diciembre de 2017, p. 12, disponible en [www.ieee.es/Galerias/fichero/docs_opinion/2017/DIEEEO128-2017_Ecocidio_RoselSoler.pdf] (consulta: 27 de marzo de 2020).

128 El Consejo de Derechos Humanos de Naciones en junio de 2014 aprobó una resolución al respecto. Llama la atención que el voto negativo (para la no creación del instrumento internacional) fue precisamente ejercido por Estados Unidos, Japón, Europa y Corea. Gonzalo Fernández Ortiz de Zárate. Alternativas al poder corporativo..., cit., p. 172.

129 Ibídem, p. 173. 
Otra posible solución es la reforma del artículo 5 del Estatuto de Roma de la Corte Penal Internacional. Según este, serán competencia de la Corte el crimen de genocidio, los crímenes de lesa humanidad, los crímenes de guerra y el crimen de agresión. Los crímenes ambientales (ecocidio) y el cohecho transnacional podrían ser dos de los delitos que incluir en las competencias de la Corte, pero hay muchas dudas sobre el grado de aceptación internacional que tendría una propuesta de esta naturaleza. Sirva también de ejemplo otro problema: los Estados Unidos no están sometidos a dicha jurisdicción. Sin embargo, sería factible, en palabras de Pérez Cepeda, "la inclusión de las personas jurídicas en el Estatuto de Roma [...] cuando cometan crímenes e agresión, genocidio, lesa humanidad y de guerra"130.

En mi opinión, la solución más viable en el corto plazo es la creación de leyes nacionales de carácter extraterritorial, como la Ley de Prácticas Corruptas de los Estados Unidos, la Bribery Act del Reino Unido o la Loi n. ${ }^{\circ}$ 2017-399, de 2017, relativa al deber de vigilancia de las empresas matrices sobre sus filiales de Francia. Estas leyes, de nueva creación, tendrían que incorporar en su ámbito competencial figuras delictivas que lesionan la seguridad humana y derechos humanos, pues sin garantizarse estos, no es posible una convivencia pacífica en el ámbito global. La creación de tribunales internacionales como los enunciados supra se encontraría, muy posiblemente, con la oposición de los países más poderosos, pues son estos, además, quienes tienen un mayor número de empresas multinacionales (por ejemplo, China y Estados Unidos). En cualquier caso, no cabe duda de que la existencia de una Corte Mundial sobre Corporaciones Trasnacionales y Derechos Humanos es muy recomendable.

También hay iniciativas que proponen una nueva interpretación de los delitos de corrupción como delitos de lesa humanidad ${ }^{131}$ y la ampliación del principio de justicia universal. Si bien estas iniciativas son interesantes, oportunas y necesarias son meramente reactivas. Por tanto, junto a ellas, debemos plantear la obligatoriedad del compliance como mecanismo detectivo y de aminoración de riesgos de naturaleza preventiva.

\section{CONCLUSIONES}

Este trabajo parte de dos argumentos esenciales que obligatoriamente debían preceder el presente análisis. El primero consiste en que las empresas desempeñan un papel

130 Ana Isabel Pérez Cepeda. "Hacia el fin de la impunidad de las empresas transnacionales por la violación de los Derechos Humanos", Revista Penal, n. ${ }^{\circ}$ 44, 2019, p. 142.

131 Ilias Bantekas. "Corruption as an International Crime...”, cit., p. 483. Contrario a tal interpretación, en virtud de argumentos vinculados a la causalidad y otros. Juan Pablo Montiel. "Sobre la inoponibilidad de la prescripción y de la cosa juzgada en casos de corrupción pública", en AA. VV. Estrategias penales y procesales de lucha contra la corrupción, Víctor Gómez Martín, Juan Pablo Montiel y Helmut Satzger (eds.), Madrid, Marcial Pons, 2018, p. 183, nota 53. 
esencial en nuestra sociedad así como en el tablero de la geopolítica, geoeconomía y geotecnología global cuyos efectos son enormes y difusos. Su rol muchas veces supera al de los propios Estados nacionales, por tal razón, estos deben intentar advertir el alcance de las actividades de aquellas para la contención de potenciales amenazas de diversa naturaleza en múltiples latitudes a través de programas de cumplimiento más eficaces que garanticen de forma prioritaria la protección de la sociedad. Las empresas deben controlar los riesgos que generan y, por ello, no deben encontrarse en un estado de cosas contrario a Derecho. En contrapartida a su libertad organizativa y de gestión asumen la responsabilidad de no lesionar los bienes jurídicos y los derechos humanos.

El segundo argumento reconoce que la responsabilidad penal de las personas jurídicas es un mecanismo de protección fundamental en las sociedades modernas que cuenta con la ventaja de que el cumplimiento normativo traslada la protección de lo reactivo a lo preventivo, incluyendo también su función detectiva.

En una segunda tarea (apartado 2.1) se ha establecido la estrecha vinculación entre la protección de los derechos humanos y los programas de cumplimiento con base en el análisis de estrategias prioritarias globales (seguridad humana, desarrollo sostenible). En esta parte del análisis se comprueba que la experiencia normativa de Francia para la protección de estos derechos es realmente atractiva, puesto que este país establece en virtud de los programas de vigilancia, que las empresas deberán realizar esfuerzos serios, reales y acreditables para mejorar su diligencia debida, pues de otro modo, serán sancionadas. Mientras, España posee un Plan de Acción Nacional de Empresas y Derechos Humanos, cuyo incumplimiento no conlleva ninguna sanción. En definitiva, España tiene tareas pendientes para conseguir que las empresas mejoren su diligencia debida y compliance para la protección de los derechos humanos.

Con el fin de demostrar la necesidad urgente de que las empresas sean responsables nacional e internacionalmente, en el trabajo también se consideraron casos en los que las empresas lesionan bienes jurídicos, el bienestar social y cuestiones que van más allá de éstas. A través de casos reales, se ha podido dejar en evidencia que el corporate crime es un fenómeno que puede vincularse directamente con el deterioro de la seguridad humana y la seguridad nacional. Por lo tanto, la implementación de mecanismos de compliance en determinadas empresas puede coadyuvar a los Estados y a los ciudadanos en la consecución de unos mejores niveles de seguridad. En otro caso, las empresas pueden retroalimentar al crimen organizado (blanqueo de capitales) y el terrorismo internacional (financiamiento del mismo), contribuir al cambio climático (deforestación y contaminación), participar de la guerra económica (espionaje industrial, fraudes) o lesionar nuestras democracias (corrupción).

En el particular caso de los Objetivos de Desarrollo Sostenible (ODS) de Naciones Unidas, como resultado del análisis efectuado afirmamos que si los Estados de verdad quieren lograr avances sustantivos en la consecución de los oDs deben instar a 
las empresas a incorporar el monitoreo y cumplimiento de sus compromisos adquiridos en esta materia a través de su compliance. Ello implicará reformar políticas, procedimientos, controles y mecanismos de supervisión y sanción. De lo contrario, la consecución de los mismos será una simple cuestión de marketing como ha sido hasta ahora la responsabilidad social corporativa. Valga como ejemplo el caso español, en el que sus empresas han logrado unos pésimos resultados suspendiendo en el logro de los 17 objetivos.

\section{REFERENCIAS}

Altamirano Dimas, Gonzalo. “Los derechos humanos de cuarta generación. Un acercamiento", en Estudios. Centro de Estudios Sociales y de Opinión Pública (CESOP), Cámara de diputados LXII [México], agosto de 2017, pp. 1-41, disponible en [www5. diputados.gob.mx/index.php/camara/Centros-de-Estudio/CESOP/Estudios-e-Investigaciones/Estudios/Los-derechos-humanos-de-cuarta-generacion.-Un-acercamiento] (consulta: 22 de mayo de 2020).

Ayala de la Torre, José María. Claves Prácticas. Compliance. Madrid, Francis Lefebvre, 2016.

Ballesteros Sánchez, Julio. "Criminalidad empresarial y Derecho penal: la responsabilidad penal de las personas jurídicas en el marco de la globalización y los llamados programas de cumplimiento efectivo", en AA. VV. Derecho Internacional Penal y Humanitario, Héctor Olásolo Alonso (coord.), Valencia, Tirant lo Blanch, 2016, pp. 227-256.

Balmaceda Hoyos, Gustavo; Rodrigo Guerra Espinosa y María Juppet Ewing. Compliance. Visión general desde una perspectiva penal y comercial. Santiago de Chile, Thompson Reuters, 2019.

Bantekas, Ilias. "Corruption as an International Crime and Crime against Humanity: An Outline of Supplementary Criminal Justice Policies", Journal of International Criminal Justice, vol. 4, n. ${ }^{\circ}$ 3, 2006, pp. 466-484.

Bock, Dennis. "Compliance y deberes de vigilancia en la empresa", en AA. VV. Compliance y teoría del Derecho penal. Madrid, Marcial Pons, 2013, pp. 107-124.

Bohoslavsky, Juan Pablo y Marcelo Torelly. "Financial Complicity. The Brazilian Dictatorship under the "macroscope", en AA. vV. Justice and Economic Violence in Transition, Dustin N. Sharp (ed.), Nueva York, Springer, 2014, pp. 233-262.

Brickey, Kathleen. "Enron's Legacy”, Buffalo Criminal Law Review, vol. 8, n. 2 , 2004, pp. 221-276. 
Bruno, Ángel. “Apuntes sobre la corrupción y la Convención Interamericana”, en AA. VV. Compliance, anticorrupción y responsabilidad penal empresaria, Nicolás Durrieu y Raúl R. Saccani (dirs.), Buenos Aires, La Ley, 2018, pp. 361-370.

Cajiga Calderón, Juan Felipe. El concepto de responsabilidad social empresarial [en línea], Centro Mexicano para la Filantropía, 2010, disponible en [www.cemefi. org/esr/images/stories/pdf/esr/concepto_esr.pdf] (consulta: 27 de marzo de 2020).

De la Cuesta González, Marta. "El porqué de la responsabilidad social corporativa", Boletín económico de ICE, n. ${ }^{\circ} 2813,2004$, pp. 45-58.

Demetrio Crespo, Eduardo. "Vulneración de Derechos Humanos por empresas multinacionales: ¿De un Derecho penal económico transnacional a un Derecho penal internacional económico?", en AA. VV. Derecho penal económico y derechos humanos, Valencia, Tirant lo Blanch, 2018, pp. 11-24.

Durán Ayago, Antonia. "Sobre la responsabilidad de las empresas por violaciones graves de los derechos humanos en terceros países", Anuario Español de Derecho Internacional Privado, n. ${ }^{\circ}$ 18, 2018, pp. 323-348.

Fernández Ortiz de Zárate, Gonzalo. Alternativas al poder corporativo. 20 propuestas para una agenda de transición en disputa con las empresas transnacionales. Barcelona, Icaria, 2016.

Fonseca Fortes Furtado, Regina. "La colaboración premiada en la Ley Brasileña de Combate a las Organizaciones Criminales: su aplicación en el presunto caso de corrupción en la empresa Petrobrás", en AA. vV. Corrupción pública y privada en el Estado de derecho, Joan Queralt Jiménez y Dulce Santana Vega (dirs.), Valencia, Tirant lo Blanch, 2017, pp. 427-435.

Francés, Pedro. Ética de los negocios, Bilbao, Desclée, 2004.

Gallizo, José y Xavier Sabi. "Bankia y la transparencia necesaria", Revista de Contabilidad y Dirección, vol. 1, n. ${ }^{\circ}$ 16, 2013, pp. 263-290.

George, Susan. Los usurpadores. Cómo las empresas transnacionales toman el poder, Barcelona, Icaria, 2015.

Gómez Doñate, Paula. "Modelo de prevención y control”, en AA. vV. Practicum Compliance 2018, Xavier Ribas (dir.), Navarra, Aranzadi, 2018, pp. 51-74.

Gutiérrez Muñoz, Clara. El estatuto de la responsabilidad penal de las personas jurídicas: aspectos de Derecho material, tesis doctoral, Universidad Autónoma de Barcelona, 2016. 
Hidalgo García, María del Mar. "La influencia de los servicios de los ecosistemas en la seguridad: el caso de la pesca", Documento de Análisis del Instituto Español de Estudios Estratégicos [en línea], n. ${ }^{\circ} 24,27$ de junio de 2018, pp. 1-15, disponible en [http://www.ieee.es/Galerias/fichero/docs_analisis/2018/DIEEEA24-2018_Servicios_Ecosistemas_Pesca_MMHG.pdf] (consulta: 27 de marzo de 2020).

Jochnick, Chris. “¿Qué implicaciones tiene la sentencia contra Chevron por \$18 mil millones de dólares?", Aportes DPLF: Revista para la Fundación del Debido Proceso, n. ${ }^{\circ} 15$, septiembre de 2011, pp. 46-47, disponible en [http://www.dplf.org/sites/ default/files/1317248743_1.pdf] (consulta: 20 de mayo de 2020).

Laborie Iglesias, Mario. "La controvertida contribución de las empresas militares y de seguridad privadas (EMSP) a la resolución de conflictos”, Cuadernos de Estrategia, n. ${ }^{\circ} 147,2010$, pp. $77-138$.

Lledó Benito, Ignacio. Corporate compliance: la prevención de riesgos penales y delitos en las organizaciones penalmente responsables. Madrid, Dykinson, 2018.

López Álvarez, Antonio. "Los partidos políticos en España: constitucionalización, régimen legal, democracia interna y corrupción”, en AA. VV. La corrupción política en España: una visión ética y jurídica, Antonio López Álvarez y Juan José García Navarro (coords.), Navarra, Aranzadi, 2016, pp. 35-50.

Maza Martín, José Manuel. Delincuencia electoral y responsabilidad penal de los partidos políticos. Madrid, Wolters Kluwers, 2018.

Montiel, Juan Pablo. "Sobre la inoponibilidad de la prescripción y de la cosa juzgada en casos de corrupción pública", en AA. VV. Estrategias penales y procesales de lucha contra la corrupción, Víctor Gómez Martín, Juan Pablo Montiel y Helmut Satzger (eds.), Madrid, Marcial Pons, 2018, pp. 171-914.

Navarrete, María Alejandra. “¿Por qué asesinan a candidatos y líderes políticos en Colombia?", en Insight Crime. Investigación y análisis del Crimen Organizado, 12 de septiembre de 2019, disponible en [https://es.insightcrime.org/noticias/analisis/ asesinan-candidatos-colombia/] (consulta: 27 de marzo de 2020).

Nieto Martín, Adán. "De la ética pública al public compliance: sobre la prevención de la corrupción en las administraciones públicas", en AA. VV. Derecho, confianza y democracia, Jerónimo Betegón y Juan Ramón de Páramo (coords.), Albacete, Bomarzo, 2013, pp. 105-130.

Nieto Martín, Adán y Beatriz García Moreno (coords.). Guía para la prevención de la corrupción en las administraciones públicas de Castilla-La Mancha. Cuenca, Ediciones Universidad de Castilla-La Mancha, 2018. 
Ontiveros Alonso, Miguel. "Casinos, compliance y sistema penal. Fundamentos del juego responsable", Anuario Mexicano de Derecho Penal Económico, n. ${ }^{\circ}$ 1, 2015, pp. 273-296.

Ortés Caselles, Joaquín y Juan Luis Jiménez González. “Efectos políticos y económicos de los escándalos de corrupción y de su difusión pública”, en AA. VV. Corrupción y desarrollo, Nicolás Rodríguez García y Fernando Rodríguez López (dirs.), Valencia, Tirant lo Blanch, 2017, pp. 45-72.

Pérez Cepeda, Ana Isabel. "Hacia el fin de la impunidad de las empresas transnacionales por la violación de los Derechos Humanos”, Revista Penal, n. ' 44, 2019, pp. 126-147.

Pérez Franco, Miguel Ángel. "Seguridad humana: ¿el complemento perfecto para nuestras estrategias de seguridad?", Revista del Instituto Español de Estudios Estratégicos, Documento de Opinión, n. ${ }^{\circ}$ 118, 2016, pp. 1-15.

Pérez Luño, Antonio Enrique. "Los derechos humanos hoy: perspectivas y retos XXII Conferencias Aranguren”, Isegoría. Revista de Filosofía Moral y Política, n. ${ }^{\circ}$ 51, julio/diciembre de 2014, pp. 465-544, disponible en [http://isegoria.revistas.csic.es/ index.php/isegoria/article/view/870/872] (consulta: 7 de marzo de 2020).

Pitrez de Aguilar Correa, Eduardo. "Conexión Derecho penal: la reconfiguración subjetiva, normativa y funcional de la política criminal en la sociedad red", AA. VV. Política criminal ante el reto de la delincuencia transnacional, Ana Isabel Pérez Cepeda (dir.), Valencia, Tirant lo Blanch, 2016, pp. 35-71.

Querol, Nuria de e Inés Gomis. "Gestión de valores y responsabilidad social”, en AA. VV. La gestión de valores en la empresa como aportación de valor, Anna Bajo Sanjuan y Nuria Villagra García (eds.), Madrid, Universidad Pontificia Comillas, 2015, pp. 81-90.

Real Academia de Ciencias Económicas y Financieras. Empresas a favor de las personas: el camino hacia el respeto de los derechos humanos. Barcelona, Ministerio de Educación Cultura y Deporte, 2016.

Reaño Peschiera, José Leandro. "La utilidad de los programas de criminal compliance para las empresas que operan en Perú", Revista de Derecho Themis, n. . 68, 2015, pp. 141-152.

Ribas, Xavier. "25 argumentos a favor del Compliance", en AA. vV. Practicum Compliance, Xavier Ribas (dir.), Pamplona, Aranzadi, 2018, pp. 34-49. 
Riofrío Martínez-Villalba, Juan Carlos. "La cuarta ola de derechos humanos: los derechos digitales", Revista Latinoamericana de Derechos Humanos, vol. 25, n. ${ }^{\circ}$, 2014, pp. 15-45, disponible en [https://www.corteidh.or.cr/tablas/r33897.pdf] (consulta: 14 de mayo de 2020).

Rojas Aravena, Francisco y Andrea Álvarez Marín. "Seguridad humana. Un estado del arte", en AA. VV. Seguridad humana: nuevos enfoques, Francisco Rojas Aravena (ed.), San José de Costa Rica, Flacso, 2012, pp. 9-32.

Rojas Rosco, Raúl; Erika Moraleja Moraleja y Roberto Gutiérrez Arranz. Compliance Laboral. Madrid, Francis Lefebvre, 2017.

Rosal Blasco, Bernardo del. Manual de responsabilidad penal y defensa penal corporativas. Madrid, Wolters Kluwer, 2018.

Ruiz-Lluch Manils, Neus. "Manual de cumplimiento: elementos esenciales”, AA. VV. Guía de implementación de compliance para pymes. Madrid, World Compliance Association, 2019, pp. 53-58.

Soler Fernández, Rosel. “El ecocidio: ¿crimen internacional?”, Documento de Opinión del Instituto Español de Estudios Estratégicos, n. ${ }^{\circ}$ 128, 21 de diciembre de 2017, pp. 1-14, disponible en [www.ieee.es/Galerias/fichero/docs_opinion/2017/ DIEEEO128-2017_Ecocidio_RoselSoler.pdf] (consulta: 27 de marzo de 2020).

Sun Beale, Sara, "Una respuesta a las críticas a la responsabilidad penal corporativa”, Anuario de Derecho Penal Económico y de la Empresa, n. . 4, 2018, pp. 25-57.

Tombs, Steve y David Whyte. La empresa criminal. Barcelona, Icaria, 2016.

Vasak, Karel. "Human Rights: A Thirty-Year Struggle: the Sustained Efforts to give Force of law to the Universal Declaration of Human Rights", en Unesco Courier, vol. 30 , n. ${ }^{\circ} 11,1977$, pp. 29-32.

Yagües Palazón, Miguel. “Los desafíos medioambientales en el espacio ultraterrestre en el marco de la segunda era espacial”, Revista del Instituto Español de Estudios Estratégicos, n. ${ }^{\circ} 12,2018$, pp. 177-214.

Zúñiga Rodríguez, Laura. Bases para un Modelo de Imputación de Responsabilidad Penal de las Personas Jurídicas, 3. a edición, Navarra, Aranzadi, 2009.

Zúñiga Rodríguez, Laura. "El concepto de criminalidad organizada transnacional: problemas y propuestas", en AA. VV. Política criminal ante el reto de la delincuencia transnacional, Ana Isabel Pérez Cepeda (dir.), Valencia, Tirant lo Blanch, 2016, pp. 159-217. 


\section{Documentos institucionales}

Cepal-Naciones Unidas. Agenda 2030 y los Objetivos de Desarrollo Sostenible. Una oportunidad para América Latina y el Caribe [en línea] (LC/G.2681-P/Rev.3), Santiago, diciembre de 2018, disponible en [https://repositorio.cepal.org/bitstream/ handle/11362/40155/24/S1801141_es.pdf] (consulta: 27 de marzo de 2020).

Comisión de las Comunidades Europeas. Libro Verde. Fomentar un marco europeo para la responsabilidad social de las empresas. Сом (2001) 366 final. Bruselas, 17 de julio de 2001, disponible en [http://www.europarl.europa.eu/meetdocs/committees/ deve/20020122/com(2001)366_es.pdf] (consulta: 27 de marzo de 2020).

Comisión Europea. Comunicación conjunta al Parlamento Europeo y al Consejo. Comunicación conjunta sobre la lucha contra las amenazas híbridas. Una respuesta de la Unión Europea. JOIN (2016) 18 final. Bruselas, 6 de abril de 2016, disponible en [https://eur-lex.europa.eu/legal-content/ES/TXT/PDF/?uri=CELEX:52016JC0018\& from=ES] (consulta: 27 de marzo de 2020).

Fondo Fiduciario de las Naciones Unidas para la Seguridad Humana. "Qué es la seguridad humana?" [en línea], 28 de noviembre de 2017, disponible en [https://www. un.org/humansecurity/es/what-is-human-security/] (consulta: 8 de mayo de 2020).

Gobierno de España. Plan de Acción Nacional de Empresas y Derechos Humanos. [Madrid], 2017, disponible en [http://www.exteriores.gob.es/Portal/es/PoliticaExteriorCooperacion/DerechosHumanos/Documents/Plan\%20de\%20Acci\%C3\%B3n\%20 Nacional\%20de\%20Empresas\%20y\%20Derechos\%20Humanos.pdf] (consulta: 7 de marzo de 2020).

Gobierno de España. Presidencia del Gobierno. Estrategia de Seguridad Nacional 2017. Un proyecto compartido de todos y para todos. [Madrid], Boletín Oficial del Estado, 2017, disponible en [https://www.dsn.gob.es/sites/dsn/files/Estrategia_de_ Seguridad_Nacional_ESN\%20Final.pdf] (consulta: 7 de marzo de 2020).

Gobierno de España. Departamento de Seguridad Nacional. Estrategia Nacional de Ciberseguridad 2019. [Madrid], junio de 2019, disponible en [www.dsn.gob.es/es/ documento/estrategia-nacional-ciberseguridad-2019] (consulta: 4 de mayo de 2020).

Holland, Nina y Benjamin Sourice. El lobby de Monsanto: un ataque contra nosotros, nuestro planeta y nuestra democracia, Bruselas, Corporate Europe Observatory, octubre de 2016, disponible en [https:/corporateeurope.org/sites/default/files/ attachments/monsanto_es_v2_web.pdf] (consulta: 5 de mayo de 2020).

Ministerio de Defensa de Perú. "Capítulo III: Política de Estado para la Seguridad y la Defensa Nacional”, en Libro Blanco de la Defensa Nacional, Lima, abril de 2005, 
disponible en [https://www.mindef.gob.pe/informacion/documentos/libroblanco/ Capitulo_III.pdf] (consulta: 6 de mayo de 2020).

Russian Federation. Russian National Security Strategy, December 2015, disponible en [http://www.ieee.es/Galerias/fichero/OtrasPublicaciones/Internacional/2016/ Russian-National-Security-Strategy-31Dec2015.pdf] (consulta: 20 de mayo de 2020).

\section{Informes}

Alianza por la Solidaridad. El caso Nejapa, Informe. [E1 Salvador], junio de 2015, disponible en [http://www.alianzaporlasolidaridad.org/especiales/tierrra/pdf/Informe_CocaCola_Salvador.pdf] (consulta: 16 de julio de 2019).

Asamblea General de Naciones Unidas. Seguimiento de la resolución 66/290 de la Asamblea General sobre Seguridad Humana. Informe del secretario general A/68/685, 23 de diciembre de 2013, disponible en [https://undocs.org/pdf?symbol=es/A/68/685] (consulta: 2 de marzo de 2020).

Commission on Human Security. Human Security Now, New York, 2003, disponible en [https://reliefweb.int/sites/reliefweb.int/files/resources/91BAEEDBA50C6907C125 6D19006A9353-chs-security-may03.pdf] (consulta: 20 de marzo de 2020).

Consejo de Derechos Humanos. Asamblea General de Naciones Unidas. Proteger, respetar y remediar: un marco para las actividades empresariales y los derechos humanos, informe A/HRC/8/5, 7 de abril de 2008, disponible en [https://observatoriorsc.org/wp-content/uploads/2013/11/Proteger_respetar_remediar_abril2008.pdf] (consulta: 2 de marzo de 2020).

Corporación Transparencia por Colombia. Así se mueve la corrupción. Radiografía de los hechos de corrupción en Colombia 2016-2018, Monitor Ciudadano tercer informe, Bogotá, mayo de 2019, disponible en [https://transparenciacolombia.org. co/Documentos/2019/Informe-Monitor-Ciudadano-Corrupcion-18.pdf] (consulta: 20 de mayo de 2020).

Institute for Economics \& Peace. Global, Index, Peace Index 2020, Measuring Peace in a Complex World. Sydney [EIP], June 2020, disponible en [http://visionofhumanity.org/app/uploads/2020/06/GPI_2020_web.pdf] (consulta: 13 de julio de 2020).

MAGBMA y FAO. Estudio de las causas de la deforestación y degradación forestal en Guinea Ecuatorial (2004-2014), República de Guinea Ecuatorial, 2018, disponible en [http://www.fao.org/3/CA0399ES/ca0399es.pdf] (consulta: 27 de marzo de 2020).

Observatorio ODS/ESADE. La contribución de las empresas españolas a los Objetivos de Desarrollo Sostenible. Segundo Informe. Barcelona, mayo de 2019, disponible en 
[https://obrasociallacaixa.org/documents/10280/825331/la_contribucion_de_las_ empresas_espanolas_a_los_ods_segundo_informe_es.pdf].

The Economist Intelligence Unit. Democracy Index 2019. A year of democratic setbacks and popular protest. New York, 2020, disponible en [https://www.in.gr/ wp-content/uploads/2020/01/Democracy-Index-2019.pdf].

Transparency International. Índice de Percepción de la Corrupción 2019. Berlín, enero de 2020, disponible en [www.proetica.org.pe/wp-content/uploads/2020/01/ CPI2019_Report_ES-WEB.pdf] (consulta: 7 de mayo de 2020).

World Economic Forum. Informe de riesgos mundiales 2018, 13. a edición, Ginebra, 2018, disponible en [https://www.mmc.com/content/dam/mmc-web/Global-RiskCenter/Files/the-global-risks-report-2018-es.pdf] (consulta: 7 de julio de 2020).

\section{Prensa}

" 10 biggest corporations make more money than most countries in the world combined", Global Justice Now [en línea], September 12, 2016, disponible en [https:// www.globaljustice.org.uk/news/2016/sep/12/10-biggest-corporations-make-moremoney-most-countries-world-combined] (consulta: 27 de marzo de 2020).

"Anticorrupción pide al juez que procese a 27 personas por la presunta venta irregular de armas de Defex a Angola", EuropaPress [en línea], 18 de abril de 2018, disponible en [http://www.europapress.es/nacional/noticia-anticorrupcion-pide-juez-procese27-personas-presunta-venta-irregular-armas-defex-angola-20180418122601 html] (consulta: 27 de marzo de 2020).

"Lafarge cement giant in terrorist funding probe", $B B C$ News Business [en línea], June 28, 2018, disponible en [https://www.bbc.com/news/business-44643703] (consulta: 27 de marzo de 2020).

"Petorca, el símbolo de la guerra por el agua en Chile", France 24 [en línea], 22 de marzo de 2018, disponible en [https://www.france24.com/es/20180322-petorca-elsimbolo-de-la-guerra-por-el-agua-en-chile] (consulta: 27 de marzo de 2020).

“¿Por qué no mejora el bienestar de los colombianos?”, Dinero [en línea] (Sección Economía: entrevista a Luis García Echeverría), 27 de septiembre de 2019, disponible en [www.dinero.com/economia/articulo/a-que-se-deben-los-pocos-avances-en-elbienestar-de-los-colombianos/277323] (consulta: 13 de marzo de 2020).

Carmen Menéndez. "Francia se prepara para la guerra espacial”, Euronews [en línea], 26 de julio de 2019, disponible en [https://es.euronews.com/2019/07/26/francia-seprepara-para-la-guerra-espacial] (consulta: 26 de julio de 2019). 
Cassin, Harry. "World Bank announces two debarments for fraudulent practices", The FCPA blog, 19 de agosto de 2020, disponible en [https://fcpablog.com/2020/08/19/ world-bank-announces-two-debarments-for-fraudulent-practices/] (consulta: 19 de agosto de 2020).

Cortés, Javier. "Protección de datos. El espionaje de los asistentes virtuales podría quedar impune", El País [en línea], 1. e agosto de 2019, disponible en [https://retina.elpais.com/retina/2019/08/01/tendencias/1564646860_938931.html] (consulta: 18 de marzo de 2020).

EFE. Agencia de Noticias. “Apple y Samsung, multadas en Italia por la obsolescencia programada", El Mundo [en línea], 25 de octubre de 2018, disponible en [www. elmundo.es/tecnologia/2018/10/24/5bd055e046163fa49c8b45aa.html] (consulta: 20 de marzo de 2020).

Endesa. "El 96\% del fraude eléctrico se debe a empresas y a particulares con un elevado nivel de consumo", Endesa. Sala de Prensa [en línea], 4 de agosto de 2015 , disponible en [https://www.endesa.com/es/prensa/news/d201608-el-96-del-fraudeelctrico-se-debe-a-empresas-y-a-particulares-con-un-elevado-nivel-de-consumo. html] (consulta: 20 de marzo de 2020).

Europa Press. "Microsoft admite que sus empleados escuchan una parte de las llamadas de Skype", Público [en línea], 8 de agosto de 2019, disponible en [https:/www. publico.es/ciencias/microsoft-microsoft-admite-empleados-escuchan-parte-llamadasskype.html] (consulta: 8 de agosto de 2019).

Juez, Beatriz. "Francia: 'El espacio es un nuevo frente a defender y debemos estar preparados", El Mundo [en línea], 25 de julio de 2019, disponible en [https://www. elmundo.es/internacional/2019/07/25/5d39c31421efa0f8508b46c9.html] (consulta: 25 de julio de 2019).

Krugman, Paul. "Rich Man's Recovery", The New York Times [en línea], September 12, 2013, disponible en [https://www.nytimes.com/2013/09/13/opinion/krugmanrich-mans-recovery.html] (consulta: 27 de marzo de 2020).

Masdeu, Jaume. "La entrada de Huawei lleva a la UE a reforzar la seguridad del 5G", La Vanguardia [en línea], 26 de marzo de 2019, disponible en [https:/www.lavanguardia.com/tecnologia/20190326/461242978052/huawei-red-5g-ciberseguridad-ue. html] (consulta: 26 de marzo de 2019).

Méndez, Rafael. “El Supremo deja impune la pesca 'pirata' en alta mar: así escapó el clan Vidal de la justicia”, El Confidencial [en línea], 10 de febrero de 2017, disponible en [https://www.elconfidencial.com/espana/2017-02-10/supremo-deja-impunepesca-pirata-alta-mar-asi-escapo-clan-vidal-justicia_1327354/]. 
Redacción Diario ElComercio.com. "Ecuador despliega buques y aviones militares por flota de pesca china en Galápagos”, El Comercio [en línea], 25 de abril de 2019, disponible en [https://www.elcomercio.com/actualidad/flota-china-aviones-ffaagalapagos.html] (consulta: 27 de marzo de 2020).

Redacción RPP Noticias. "Un año después, el caso Odebrecht sigue sacudiendo la política peruana”, RPP Noticias [en línea], 21 de diciembre de 2017, disponible en [http://rpp.pe/politica/judiciales/que-es-el-caso-odebrecht-y-como-afecta-al-perunoticia-1090099] (consulta: 27 de marzo de 2020).

Soto, Nanqui. “Acción/Cortamos el agua en las oficinas de Florentino mientras siguen restringiendo agua a los indígenas de Guatemala", GreenPeace Noticias [en línea], 13 de abril de 2018, disponible en [https://es.greenpeace.org/es/noticias/actividadacs/] (consulta: 27 de marzo de 2020).

Unidad Investigativa. "Así opera la poderosa mafia transnacional que ronda a la Registraduría", El Tiempo [en línea], 26 de enero de 2020, disponible en [https://www. eltiempo.com/unidad-investigativa/asi-opera-la-mafia-transnacional-que-ronda-ala-registraduria-404530] (consulta: 20 de marzo de 2020).

United States-Department of Justice, Office of Public Affairs. "Volkswagen AG Agrees to Plead Guilty and Pay \$4.3 Billion in Criminal and Civil Penalties; Six Volkswagen Executives and Employees are Indicted in Connection with Conspiracy to Cheat U.S. Emissions Tests", Justice News [en línea], January 11, 2017, disponible en [https:// www.justice.gov/opa/pr/volkswagen-ag-agrees-plead-guilty-and-pay-43-billioncriminal-and-civil-penalties-six] (consulta: 27 de marzo de 2020).

\section{Multimedia}

Carr, Erin Lee (dir.). "Venta en corto y farmacéuticas", documental: Dirty Money/ Netflix, temporada 1, episodio 3, 26 de enero de 2018.

Jacobson, Kristi (dir.). "El banco de los cárteles”, documental: Dirty Money/Netflix, temporada 1, episodio 4, 26 de enero de 2018.

\section{Normas jurídicas}

Asamblea General de Naciones Unidas. Declaración Universal de Derechos Humanos. Resolución n. ${ }^{\circ} 217$ A III, 10 de diciembre de 1948.

Argentina. Ley 27.401, del 8 de noviembre de 2017, de Régimen de Responsabilidad Penal aplicable a las Personas Jurídicas Privadas. Boletín Oficial, n. ${ }^{\circ} 33763$, del 1. ${ }^{\circ}$ de diciembre de 2017. 
España. Ley 10/2010, del 28 de abril, de Prevención de Blanqueo de Capitales y de la Financiación del Terrorismo. Boletín Oficial del Estado, n. ${ }^{\circ} 103,29$ de abril de 2010.

España. Ley Orgánica 5/1985, del 19 de junio, del Régimen Electoral. Boletín Oficial del Estado, n. ${ }^{\circ}$ 147, del 20 de junio de 1985.

España. Ley Orgánica 3/2015, del 30 de marzo, de control de la actividad económico financiera de los Partidos Políticos, por la que se modifican la Ley Orgánica 8/2007, del 4 de julio, sobre financiación de los Partidos Políticos, la Ley Orgánica 6/2002, del 27 de junio, de Partidos Políticos y la Ley Orgánica 2/1982, del 12 de mayo, del Tribunal de Cuentas. Boletín Oficial del Estado, n. ${ }^{\circ}$ 77, del 31 de marzo de 2015.

España. Real Decreto 304/2014, del 5 de mayo, por el que se aprueba el Reglamento de la Ley 10/2010, del 28 de abril, de prevención del blanqueo de capitales y de la financiación del terrorismo. Boletín Oficial del Estado, n. ${ }^{\circ}$ 110, del 6 de mayo de 2014.

Francia. Loi n. ${ }^{\circ}$ 2016-1691, du 9 décembre 2016, relative à la transparence, à la lutte contre la corruption et à la modernisation de la vie économique. Journal officiel de la République française JORF n. ${ }^{\circ}$ 0287, du 10 décembre 2016.

Francia. Loi n. 2017-399, du 27 mars 2017, relative au devoir de vigilance des sociétés mères et des entreprises donneuses d'ordre. Journal officiel de la République française JORF n. ${ }^{\circ} 0074$, du 28 mars 2017.

Perú. Decreto Supremo n. ${ }^{\circ}$ 012-2017-DE, que aprueba la Política de Seguridad y Defensa Nacional, del 22 de diciembre de 2017. Diario Oficial del Bicentenario El Peruano, 22 de diciembre de 2017, n. ${ }^{\circ} 14332$.

United Kingdom. Bribery Act, April 8, 2010.

United States of America. Foreign Corrupt Practices Act (FCPA). Public Law 95-213, 91 STAT. 1494, December 19, 1977.

United States Sentencing Commission. Federal Sentencing Guidelines for Organizations (FSGO), November 1, 1991.

\section{Jurisprudencia y otra documentación judicial}

España. Sentencia del Tribunal Constitucional n. ${ }^{\circ}$ 246/1991, del 19 de diciembre.

España. Sentencia del Tribunal Supremo n. ${ }^{\circ}$ 974/2016, del 23 de diciembre.

TEDH. Sentencia del Tribunal Europeo de Derechos Humanos, n. ${ }^{\circ} 48939 / 99$, caso Öneryildiz vs. Turquía GC, del 30 de noviembre de 2004. 
United States District Court. The Eastern District of New York. HSBC's Deferred Prosecution Agreement, Statement of Facts. Case 1:12-cr-00763-ILG Document 3-3. (United States of America vs. HSBC Bank USA, N. A. and HSBC Holdings PLC). December 11, 2012, disponible en [https://www.justice.gov/sites/default/files/opa/ legacy/2012/12/11/dpa-attachment-a.pdf] (consulta: 27 de marzo de 2020). 